\title{
Süreç Verilerinin Normal Dağılışa Uymadığı Durumlarda Kullanılan Süreç Yetenek Analizi Yöntemleri Üzerine Bir Araştırma $^{1}$
}

\author{
Esin Cumhur YALÇIN \\ Sorumlu Yazar, Kırklareli Üniversitesi, İ̈BF, Ekonometri Bölümü \\ esincumhur.yalcin@klu.edu.tr, ORCID: 0000-0002-0457-4971 \\ Cenk ÖZLER \\ Dokuz Eylül Üniversitesi, İ̈BF, Ekonometri Bölümü \\ cenk.özler@deu.edu.tr,ORCID:0000-0001-7773-2216 \\ Ali Kemal ŞEHIRLIOOĞLU \\ Dokuz Eylül Üniversitesi, İ̈BF, Ekonometri Bölümü \\ alikemal.sehirlioglu@deu.edu.tr, ORCID: 0000-0001-5190-6740
}

\begin{abstract}
$\ddot{\mathbf{O} z}$
Literatürde ilk önerilmiş olan süreç yetenek indeksleri, süreç verilerinin normal dağılması, kalite karakteristiklerine ait toleransların simetrik olması ve sürecin kontrol altında olması varsayımları altında çalışmaktadır. İlerleyen çalışmalarda, süreç verilerinin normal dağıldığ 1 ve toleransların asimetrik olduğu, süreç verilerinin asimetrik bir dağılıma uyduğu ve toleransların simetrik olduğu durumlar için bazı yetenek indeksleri önerildiği görülmektedir. Bu çalıșmanın amacı, literatürdeki diğer çalışmalardan farklı olarak, toleransların asimetrik ve süreç verilerinin dağılımının normal olmadığı durumlar için yeni bir süreç yetenek indeksi $\left(C_{\text {pac }}\right)$ önermektir. Asimetrik toleranslı ve asimetrik dağılımlı süreçlerin tanımlanması için Pearson dağılım ailesi ile çalışılmıștır. Önerilen indekste baz dağılım ile süreç dağılımının dört temel bileşeni karşılaştırılmaktadır. Dağılımın hedef değerden uzaklığı, basıklık ve çarpıklık değerlerindeki değişimi ile alt ve üst spesifikasyon limitlerine olan yakınlığı dikkate alınmıștır. Önerilen indeksin çeşitli durumlarda gösterdiği performans örneklerle incelenmiştir. Sonuç olarak $C_{p a c}$ indeks değeri, süreç dağılımının basıklık değeri arttıkça ve süreç dağılım verileri hedef değere yaklaştıkça artmakta, çarpıklık değerindeki artışlarda azalmaktadır.
\end{abstract}

Anahtar Kelimeler: Asimetrik Tolerans, Asimetrik Dağılım, Süreç Yetenek İndeksi, Pearson Dağılım Ailesi Jel Sinıflandırma Kodları: C14, C43, C46

A Research on Capability Analysis Methods Used in Cases of Non-Normality Distributed Process Data ${ }^{2}$ Abstract

Early proposed process capability indices in the literature work under the assumptions that the process data is normally distributed, the tolerances of quality characteristics are symmetric and the process is under control. In further studies it's seen that various capability indices are proposed in cases where the process data is distributed normally and the tolerances are asymmetric, the process data is asymetrically distributed and the tolerances are symmetric. Aim of this study, apart from other studies in the literature, in this study, a new process capability index $\left(C_{p a c}\right)$ is proposed for the cases where the tolerances are asymmetric and the distribution of the process data is not normal. Pearson distribution family was studied in order to define asymmetric toleranced and asymmetric distributed processes. In the proposed index, the four main components of the base distribution and the process distribution are compared. The distance of the distribution from the target value, the change in kurtosis and skewness values and its proximity to the upper and lower specification limits were taken into consideration. The performance of the proposed index in various cases is examined with examples. As a result, the $C_{p a c}$ index value increased as the kurtosis value of the process distribution increased and as the process distribution data approached the target value, and decreased as the skewness value increased.

Keywords: Asymmetric Tolerance, Asymmetric Distribution, Process Capability Indices, Pearson Distribution Family.

Jel Classification Codes: C14, C43, C46

${ }^{1} \mathrm{Bu}$ çalışma yazarlardan Prof.Dr. Cenk ÖZLER danışmanlığında diğer yazar Esin Cumhur YALÇIN tarafindan hazırlanan "Süreç Verilerinin Normal Dağılışa Uymadığı Durumlarda Kullanılan Süreç Yetenek Analizi Yöntemleri Üzerine Bir Araştırma" başlıklı doktora tezinden türetilmiştir.

${ }^{2}$ Extended abstract is presented at the end of the article.

Geliş Tarihi (Received): 25.11.2019 - Kabul Edilme Tarihi (Accepted): 21.06.2020

Atıfta bulunmak için/Cite this paper:

Yalçın, E. C., Özler, C. ve Şehirlioğlu, A. K.. (2020) Süreç verilerinin normal dağılışa uymadığı durumlarda kullanılan süreç yetenek analizi yöntemleri üzerine bir araştırma. Çankırı Karatekin Üniversitesi İ̈BF Dergisi, 10 (1), 245-276. Doi: 10.18074/ckuiibfd.650499. 


\section{Giriş}

Süreç yetenek indeksleri, üretim süreçlerinin, bu süreçlerde üretilen ürünlerin spesifikasyon limitlerini (toleransları) karşılama yeteneğini özetleyen göstergelerdir. Süreç yeteneğinin istatistiksel ölçümü için yapılan ilk çalışmalarda bazı varsayımların sağlanması gerekmektedir. İlk olarak önerilen $C_{p}$ indeksi, temel olarak sürecin spesifikasyon limitlerinin sürecin doğal tolerans aralığ $\breve{1}_{(6 \sigma)}$ içinde olup olmadığını araştırmaktadır (Sullivan, 1984, s. 15-21). Daha sonra süreç ortalamasının konumunu da dikkate alarak $C_{p k}$ indeksi önerilmiștir (Kane, 1986, s. 41-52). Kontrol limitlerinin dişında, $n$ örnek hacmine dayalı örnek aritmetik ortalamasının elde edilme olasılığı ile $C_{p k}$ arasındaki ilişkiler araştırılmıştır (Porter ve Oakland, 1991, s.437-448). Bu ilişkiler faydalı olmasına rağmen süreç yeteneğinin yorumlanması açısından daha kolay ifadeler bulunmaktadır. Ayrıca Gensidy (1985), Barnett (1996) ve Coleman (1991) $C_{p}$ ve $C_{p k}$ arasındaki ilişkiyi incelemiştir (Kotz ve Johnson, 1993, s. 53). Literatürde Taguchi indeksi olarak da anılan $C_{p m}$ indeksi hedef değer ile süreç ortalaması arasındaki farkı dikkate almaktadır (Chan, 1988, s. 162-175). Bu indekslerin hepsi süreç verilerine ilişkin bazı varsayımlar altında kullanılmaktadır. Bu varsayımlar sürecin kontrol altında olması (kararlılığı), ürün çıktılarının yaklaşık olarak normal dağılıyor olması ve toleransların bir hedef değer etrafinda simetrik olmasıdır. Süreç karakteristiğinin dağılımı normal olmadığında, süreç yetenek indekslerinin hesaplanmasında kullanılan klasik yöntemler, süreç yeteneğinin yorumlanmasinda hatalara neden olacaktır.

Üretim endüstrisinde hedef değerin $(T)$ süreç spesifikasyon aralığının orta noktasında $(m)$ olmadığ 1 pek çok durumla karşılaşılabilir $(T \neq m)$. Asimetrik toleranslı durumlar için süreç yetenek indeksleri Boyles (1994), Vannman (1997), Chen (1998), Chen vd. (1999), Chen ve Pearn (2001), Pearn vd. (2001) tarafindan ele alınmıştır. İlgili çalışmalarda süreç verilerinin normal dağılış gösterdiği varsayılmaktadır.

1990'l1 yıllarla birlikte süreç karakteristiğinin normal olmadığ durumlar ile ilgili süreç yetenek indeksi geliştirme çalışmalarına başlanmıştır. $\mathrm{Bu}$ çalışmalar verilerin normal hale getirilmesi için dönüşüm teknikleri uygulama, bilinen belirli dağılımlar (Burr Dağılımı, Log-normal Dağılım, Weibull Dağılımı vb.) için süreç yetenek indeksleri geliştirme, sağlam (robust) teknikleri uygulama ve asimetrik dağılımlar için yeni indeksler ortaya koyma şeklinde özetlenebilir. Ancak bütün bu çalışmaların her birinde tolerans limitleri simetrik olarak ele alınmıştır. Diğer bir deyişle, kalite karakteristiğinin hedef değerinin, spesifikasyon limitlerinin ortalamasına eşit olduğu varsayılmıştır. Bununla birlikte, son yıllarda asimetrik dağılıma ve simetrik toleransa sahip süreçler için kullanılabilecek süreç yetenek indeksleri için birtakım yaklaşımlar önerilmiştir. Bu önerilerden biri Box-Cox dönüşümü, Johnson dönüşümü ve Kantil dönüşümü gibi veri dönüşüm tekniklerinin kullanılmasıdır. Somerville ve Montgomery (1996), Kotz ve 
Loveplace (1998), Tang ve Than (1997) bu dönüşümler için çeşitli çalışmalar yapmıştır. Genel olarak dönüşümlerde orijinal ölçeğe geçerken yapılan hesaplamalarda bazı sorunlar ortaya çıkmaktadır. İkinci bir yöntem ise bilinmeyen bir dağılım yerine, deneysel bir dağılım ya da üç-dört parametreli bilinen bir dağılım ile çalışmaktır. Bu konuyla ilgili olarak Clements (1989), Pearn ve Kotz (1992), Franklin ve Wasserman (1991, 1992), Shore (1998) ve Polansky (1998) çeşitli çalışmalar yapmıştır. Castagliola (1996) Burr dağılımını kullanarak uygun olmayan parçaların oranını tahmin etmiş ve normal olmayan veriler için süreç yetenek indeksleri elde etmeye çalışmıştır. Bu yöntem oldukça karmaşık ve büyük örnekler gerektirmektedir. Üçüncü bir yöntem ise sağlamlılığ1 (robustness) arttırmak için süreç yetenek indekslerinin standart tanımlarının tekrar düzenlenmesidir. $\mathrm{Bu}$ yaklaşımın amacı, dağılımın şekline mümkün olduğunca duyarsız süreç yetenek indeksleri elde etmektir (Pearn vd., 1992; Rodriguer, 1992). Uygulamada bu yaklaşım memnun edici sonuçlar vermemektedir. Dördüncü bir yöntem ise yeni indeksler geliştirmek için deneysel argümanların kullanılmasıdır. Bai ve Choi (1997), Choobineh ve Branting (1986)'in yaklaşımına dayanarak ağırlıklandırılmış varyans (WV) süreç yetenek indeksleri öngörmüşlerdir. Wu ve diğerleri (1999) ise bu metodu geliştirerek yeni ağırlıklandırılmış varyans süreç yetenek indeksleri önermişlerdir. Chang ve diğerleri (2002) ağırlıklandırılmış standart sapma (WSD) metoduna dayalı çarpık dağılımlar için basit süreç yetenek indeksleri geliştirmiştir. Bu yöntem ile süreç ortalamasının üstünde ve altında sapmalar hesaplanarak, popülasyona göre çarpıklık derecesi göz önüne alınıp, düzeltilmiş süreç yetenek indeks değerleri elde edilmektedir. Popülasyon simetrik olduğunda bu indeksler standart süreç yetenek indekslerine indirgenir. Ayrıca Kotz ve Johnson (2002) çalışmalarında normal olmamanın sonuçlarını ve sorunlarını tartışmışlardır. ${ }^{3}$

Son dönem yapılan çalışmalarda ise süreç yetenek indekslerinin hesaplanmasında Bayesyen yaklaşımlar, bulanık sistemler, farklı süreç dağılımları için uygulama örnekleri ve çok değişkenli süreç yetenek indeksleri üzerinde odaklanılmıştır. Bu bağlamda Mondal (2015) süreç yeteneğinin varyasyonlarının sağlamlılık açısından açıklanması için bir yaklaşım öne sürmüş ve süreç yetenek indekslerinin sağlamlılığın yedek bir ölçüsü olarak kullanılabileceğini önermiştir (Mondal, 2015, s. 101). Kasnif ve diğerleri (2016) farklı bir yaklaşım öne sürerek farklı asimetriye sahip süreçlerde Gini ortalama farkı (GMD)'nı kullanarak temel süreç yetenek indeksleri ile karşılaştırma yapmış ve bu noktada GMD tabanlı süreç yetenek indeksleri önermiştir. Weibull, lognormal gibi farklı dağılımlar için normal olmayan süreç yetenek indeksleri ile ilgili çalışmalar son dönemlerde de devam etmiştir (Piña-Monarrez, 2015, s. 1325). Binomial dağılımlar için lojistik regresyon modellemeleri ile süreç yetenek indeksleri tahmin edilmiştir (Charki vd., 2015, s. 1656). Petros (2016) binom dağılımının yanı sıra poisson dağılımına sahip süreçler için süreç yetenek indekslerinin performansını incelemiştir. Süreç

\footnotetext{
${ }^{3}$ Süreç yetenek indeksleri ile ilgili detaylı bilgi için Kotz ve Johnson (1993) ve Kotz ve Lovelace (1998) çalışmaları incelenebilir.
} 
yetenek indekslerinin hesaplanması için örneklem dağılımının tahmin edilmesinde Bayesyen yaklaşımlar da ele alınmıştır. Bayesyen yaklaşım ile gerçek olasılık dağılımı arasında karşılaştırma çalışmaları yapılmış ve süreç yetenek indekslerinin performansı incelenmiştir (Seifi vd., 2017, s. 2554). Özellikle 20. yüzyılda ileri sürülen süreç yetenek indeks çalışmalarında verilerin bulanıklaştırılması ve normal olmayan süreçler için indekslerin performansının değerlendirilmesi öne çıkmaktadır. Örneğin, Senvar ve Kahraman (2014, 2014a) normal olmayan süreçlerde kullanılabilecek bulanık süreç yetenek indeksleri önermiştir. Kahraman ve diğerleri ise (2017) çalışmasında sezgisel bulanık kümelerle klasik bulanık süreç yetenek indekslerini geliştirmiş ve bulanık süreç yeterlilik analizlerinin geliştirilmesinde sezgisel bulanık sayılar ve aralık değerli sezgisel bulanık kümeleri kullanmıştır. Son dönemde bulanık süreç yetenek indeksleri ile ilgili pek çok çalışma yapılmıştır (Parchami vd., 2014, s. 1122-1132). Diğer taraftan Chen ve diğerleri (2017) Boole eşitsizliği ve DeMorgan yasasını kullanarak asimtotik alt güven limiti (LCL) için temel süreç yetenek indekslerinin performanslarını farklı vakalarda incelemişlerdir. Hsu ve diğerleri (2016) ise Boole eşitsizliği ve DeMorgan yasası ile $C_{p u}, C_{p l}$ ve $S_{p k}$ süreç yetenek indeksleri için güven aralıklarını geliştirmiştir. Yang ve diğerleri (2015) tarafindan gerçekleştirilen çalışmada, süreçlerin olasılık yoğunluk fonksiyonlarında yüksek yoğunluğa sahip fonksiyon alanı baz alınarak yeni bir süreç yetenek indeks ailesi önerilmiştir. Böylelikle asimetrik dağılım ve asimetrik tolerans limitlerine sahip süreçler için doğal bir tolerans bölgesi tanımlanmıştır. Aynı zamanda asimetrik tolerans aralığı ve normal olmayan dağılıma sahip süreçlerde çok değişkenli süreç yetenek indeksleri için de çalışmalar hız kazanmıştır. (Dianda vd. 2015, s. 2354; Pan vd., 2016, s.4648; Chatterjee ve Chakraborty, 2017, s. 291-295).

$\mathrm{Bu}$ çalışmada amaçlanan, kalite karakteristiğinin asimetrik toleransa sahip ve süreç verilerinin dağılışının normal olmadığı durumlarda da kullanılabilecek bir indeks ortaya koymaktır. Önerilen indeksi belirlemede temel dayanak, asimetrik toleranslı durumlarda süreç verilerinin uyması istenen dağılımın, (i) verilerin hedef değer etrafında yoğunlaştığı, (ii) toleranslara yaklaştıkça süreç verilerinin frekansının azaldığı ve (iii) toleransların dışında herhangi bir verinin olmadığı bir asimetrik (çarpık) dağılım olması gerektiği fikri olmuştur. Bir süreç yetenek analizinde eldeki mevcut bilgiler spesifikasyon limitleri ile hedef değerdir. Bu koşullar altında sonsuz farklı dağılış tanımlanabilir. Çalışmada, bu dağılışlardan modu hedef değerde olan ve sınırları spesifikasyon limitlerine eşit olan diğer bir ifadeyle kalite karakteristiği için istenen koşulları sağlayan dağılış baz dağılım olarak adlandırılmıştır. Alt ve üst spesifikasyon limitleri sürecin üretim aralığını kısıtlaması sebebiyle ve ayrıca hedef değerin alt ve üst spesifikasyon limitlerinin tam ortasında bulunması zorunlu olmadığı için baz dağılım olarak normal dağılışın kullanılması uygun olmamaktadır. Hedef değerin alt ve üst spesifikasyon limitlerinin orta noktasından farklı olduğu durumlarda baz dağılımın asimetrik, her iki uçtan sınırlı, tek modlu bir dağılış olması gerektiği açıktır. Bu kısıtları sağlayan dağılış olarak Pearson Tip I dağılışı önerilmiştir. Baz dağılımın her iki 
uçtan sınırlı ve simetrik olması durumunda ise Pearson Tip II dağılışı kullanılabilir. $\mathrm{Bu}$ çalışmada, pratikte sürecin ürettiği verilerin uyduğu dağılıma "proses (süreç) dağılımı" denilmiştir. Asimetrik toleranslar için bir baz dağılımın tanımlanmasında ve proses (süreç) dağılımın belirlenmesinde Pearson dağılım ailesinden yararlanılmıştır. Ardından, baz dağılım ile süreç dağılımının karşılaştırılmasına dayanan bir süreç yetenek indeksi önerilmiştir. Bu indeks baz dağılım ile süreç dağılımın yer ölçülerinin (modunun), yayılmalarının, çarpıklıklarının ve basıklıklarının karşılaştırılmasına olanak sağlamakta ve aynı zamanda ürüne ait spesifikasyon limitlerinin ne derece karşılandığını dikkate almaktadır.

Çalışma dört bölüm olarak tasarlanmıştır. İkinci bölümde Pearson Dağılış ailesi hakkında teorik bilgi verilmektedir. Üçüncü bölümde önerilen yeni indeksin ( $C_{p a c}$ ) tanıtılması ve indeksin performansını sınayan çeşitli durumlar için uygulamalara yer verilmektedir. Sonuç bölümünde de indeksin değerlendirilmesi ve geliştirilmesi için önerilerde bulunulmaktadır.

\section{Pearson Dağılış Ailesi}

Çalışmada asimetrik toleranslı durumlarda, üretim süreci tarafından üretilmesi istenen bir asimetrik dağılımın ne olması gerektiğini bulmak ve üretim sürecinin gerçekte ürettiği verilerin, bu istenen dağılıma ne kadar yaklaştığını belirlemek için Pearson dağılım ailesi ile çalışılmıştır. Bu bağlamda, önerilen indeksin bileşenlerinin hesaplanması ve dağılıma ait parametrelerin elde edilmesi için Pearson dağilım ailesinin tanıtılması önem arz etmektedir.

Rassal değişken $y$ için $\mu_{r}^{\prime}$ orijine gore r.nci moment ve $\mu_{r}$ ortalamaya gore r.nci moment olduğu varsayılsın. Böylece $\mu_{1}^{\prime}$ ve $\mu_{2}$ rassal değişkenin sırasıyla ortalaması ve varyansı olarak ifade edilir. Herhangi bir olasılık yoğunluk fonksiyonunun belirlenmesi için kullanılan bir yaklaşım, veri setine uyumlu olan Pearson dağılım sistemini kullanmaktır. Pearson dağılım sistemi aşağıdaki diferansiyel denklemin çözümü ile tanımlanabilir:

$$
\frac{d f(y)}{d y}=\frac{(y+a) f(y)}{b_{0}+b_{1} y+b_{2} y^{2}}
$$

Burada $m=-a$ mod değeri olarak tanımlanır (Elderton ve Johnson, 1969, s.35). Veri setinden elde edilen ilk dört moment bilgisi kullanılarak bilinmeyen dört parametre tahmin edilebilir. Eşitlik (1)' de verilen diferansiyel denklem çözüldüğünde Pearson dağılımlarının momentleri arasındaki tekrarlı ilişki aşağıdaki gibidir (Elderton ve Johnson, 1969, s.42).

$$
a \mu_{n}^{\prime}+n b_{0} \mu_{n-1}^{\prime}+(n+1) b_{1} \mu_{n}^{\prime}+(n+2) b_{2} \mu_{n+1}^{\prime}=-\mu_{n+1}^{\prime},
$$


$n=0,1,2,3$ değerleri kullanılarak $\mu_{0}^{\prime}=1$ iken tüm gerekli momentler $\mu_{1}^{\prime}, \mu_{2}^{\prime}, \mu_{3}^{\prime}, \mu_{4}^{\prime}$ aşağıdaki dört eşitlik ile elde edilebilir.

$$
\begin{aligned}
& a+b_{1}+2 b_{2} \mu_{1}^{\prime}=-\mu_{1}^{\prime} \\
& a \mu_{1}^{\prime}+b_{0}+2 b_{1} \mu_{1}^{\prime}+3 b_{2} \mu_{2}^{\prime}=-\mu_{2}^{\prime} \\
& a \mu_{2}^{\prime}+2 b_{0} \mu_{1}^{\prime}+3 b_{1} \mu_{2}^{\prime}+4 b_{2} \mu_{3}^{\prime}=-\mu_{3}^{\prime} \\
& a \mu_{3}^{\prime}+3 b_{0} \mu_{2}^{\prime}+4 b_{1} \mu_{3}^{\prime}+5 b_{2} \mu_{4}^{\prime}=-\mu_{4}^{\prime}
\end{aligned}
$$

$a, b_{o}, b_{1}$ ve $b_{2}$ parametreleri Eşitlik (3-4-5-6)' dan elde edilebilir. Yeni bir rassal değişken $x$ tanımlandığında $\left(x=y-\mu_{1}^{\prime}\right) x$ ' in ortalaması orijine kayar (örneğin, $x$ rassal değişkeni için $\left.\mu_{1}^{\prime}=\mu_{1}=0\right)$ ve Eşitlik (3-4-5-6) aşağıdaki dört eşitliğe dönüşür:

$$
\begin{aligned}
& a+b_{1}=0 \\
& b_{0}+3 b_{2} \mu_{2}^{\prime}=-\mu_{2}^{\prime} \\
& a \mu_{2}^{\prime}+3 b_{1} \mu_{2}^{\prime}+4 b_{2} \mu_{3}^{\prime}=-\mu_{3}^{\prime} \\
& a \mu_{3}^{\prime}+3 b_{0} \mu_{2}^{\prime}+4 b_{1} \mu_{3}^{\prime}+5 b_{2} \mu_{4}^{\prime}=-\mu_{4}^{\prime} .
\end{aligned}
$$

Eğer $\beta_{1}=\mu_{3}^{2} / \mu_{2}^{3}$ ve $\beta_{2}=\mu_{4} / \mu_{2}^{2}$ ise Eşitlik (3-4-5-6) denklem sistemi kullanıldığında aşağıdaki eşitlikler elde edilebilir.

$$
\begin{aligned}
& a=\frac{\sigma \sqrt{\beta_{1}}\left(\beta_{2}+3\right)}{B} \\
& b_{0}=-\frac{\sigma^{2}\left(4 \beta_{2}-3 \beta_{1}\right)}{B} \\
& b_{1}=-\frac{\sigma \sqrt{\beta_{1}}\left(\beta_{2}+3\right)}{B} \\
& b_{2}=-\frac{\left(2 \beta_{2}-3 \beta_{1}-6\right)}{B}
\end{aligned}
$$

Burada,

$$
B=10 \beta_{2}-12 \beta_{1}-18^{\prime} \text { 'dir. }
$$


Pearson dağ 1 lım sistemi $b_{0}+b_{1} x+b_{2} x^{2}$ denkleminin köklerine ve parametre değerlerine göre oluşur. Bu eşitsizlik iki köke sahip olduğu durumlarda ana tipler tanımlanır. Diğer taraftan, bu denklem çoklu köke ya da tek köke $\left(b_{2}=0\right)$ ya da sabite $\left(b_{1}=b_{2}=0\right)$ sahip olduğu durumlarda geçiş tipleri tanımlanır. Ana tipler aşağıdaki gibi gösterilebilir:

a) Kökler gerçek ve zıt (işaretli), Tip I, her iki taraftan sınırlı,

b) Kökler gerçek ve aynı(işaretli), Tip VI, tek taraftan sınırlı,

c) Kökler karmaşı, Tip IV, her iki taraftan sonsuz.

$x$ rassal değişkeni için Eşitlik (1)' deki diferansiyel denklemin parametreleri yerine köklerinin gösterimi aşağıdaki gibidir (Dündar ve Şehirlioğlu, 2014, s. 43).

$$
\begin{aligned}
& r_{1}=\frac{-b_{1}+\sqrt{b_{1}^{2}-4 b_{0} b_{2}}}{2 b_{2}} \\
& -r_{2}=\frac{-b_{1}-\sqrt{b_{1}^{2}-4 b_{0} b_{2}}}{2 b_{2}}
\end{aligned}
$$

Bu çalışmada sadece Tip I ve Tip VI dağılımları incelenmiştir.

\subsection{Pearson Tip I Dağılımı: Beta Dağılımı}

Tip I için Pearson diferansiyel denkleminin çözülmesi sonucunda elde edilen olasılık yoğunluk fonksiyonu aşağıdaki gibidir (Dündar ve Şehirlioğlu, 2014, s. 46).

$$
f(x)=K\left(\mathrm{r}_{1}-x\right)^{m_{1}}\left(\mathrm{x}+\mathrm{r}_{2}\right)^{m_{2}} \quad-r_{2}<x<r_{1}
$$

Burada $m_{1}$ ve $m_{2}$ şekil parametreleridir ve aşağıdaki gibi tanımlanmaktadır.

$$
\begin{aligned}
& m_{1}=\frac{1}{b_{2}} \frac{a+r_{1}}{r_{1}+r_{2}} \\
& m_{2}=\frac{1}{b_{2}} \frac{r_{2}-a}{r_{1}+r_{2}}
\end{aligned}
$$

Burada $K$ normalizasyon sabiti olup aşağıdaki gibi elde edilir: 


$$
K=\frac{1}{\left(r_{1}+r_{2}\right)^{m_{1}+m_{2}+1} B\left(m_{2}+1, m_{1}+1\right)}
$$

Burada $B(p, q)$ parametreleri $p$ ve $q$ olan Beta fonksiyonudur.

Şekil parametrelerinin işaretlerine göre Tip I dağılışı B-Biçimli (Bell Shape-B), J Biçimli (J Shape-J) ve U Biçimli (U Shape-U) olabilir. Bu durum Tablo 1' de tanımlanmıştır.

Tablo 1: Tip I Dağılımında Parametre ve Biçim İlişkisi

\begin{tabular}{|l|l|}
\hline Parametreler & Dağılış Biçimi \\
\hline$m_{1}>0$ ve $m_{2}>0$ & B-biçimli \\
\hline$m_{1}>0$ ve $m_{2}<0$ & J-biçimli (sola çarpık) \\
\hline$m_{1}<0$ ve $m_{2}>0$ & J-biçimli (sağa çarpık) \\
\hline$m_{1}<0$ ve $m_{2}<0$ & U-biçimli \\
\hline
\end{tabular}

Tip I dağılışı sağa çarpık ise $\left|r_{2}\right|<r_{1}$ ve $a>0$, sola çarpık ise $\left|r_{2}\right|>r_{1}$ ve $a<0$ olur.

\subsection{Pearson Tip VI Dağılımı: İkinci Tip Beta Dağglımı}

Tip VI dağılımı sınır değerlerinden biri sonsuza giderken oluşan bir dağglımdır. Köklerin işareti aynıdır. Pearson Tip VI sağa çarpık dağılımlar için köklerin sıralaması, $-r_{1}<-r_{2}<0$, sola çarpık dağılımlar ise $0<r_{1}<r_{2}$ 'dir. Olasılık yoğunluk fonksiyonları ve biçim parametreleri sağa çarpık dağılımlar için,

$$
\begin{array}{ll}
f(x)=K\left(r_{1}+x\right)^{m_{1}}\left(r_{2}+x\right)^{m_{2}} & -r_{2}<x<\infty \\
m_{1}=\frac{1}{b_{2}} \frac{r_{1}-a}{r_{1}-r_{2}} & \\
m_{2}=\frac{1}{b_{2}} \frac{a-r_{2}}{r_{1}-r_{2}} &
\end{array}
$$

'dir. Sağa çarpık Tip VI dağılımlarında $K$ normalizasyon sabiti Eşitlik (21)' de gösterilmektedir.

$$
K=\frac{1}{B\left(-m_{1}-m_{2}-1 ; m_{2}+1\right)\left(r_{1}-r_{2}\right)^{m_{1}+m_{2}+1}} .
$$

Sola çarpık Tip VI dağılımları için ise olasılık yoğunluk fonksiyonu Eşitlik (22)' de ifade edilmektedir. 


$$
f(x)=K\left(r_{1}-x\right)^{m_{1}}\left(r_{2}-x\right)^{m_{2}} \quad-\infty<x<r_{1}
$$

Burada $m_{1}$ ve $m_{2}$ değerleri Eşitlik (23) ve Eşitlik (24)' teki şekliyle hesaplanmaktadir.

$$
\begin{aligned}
& m_{1}=\frac{1}{b_{2}}\left[-\frac{r_{1}+a}{r_{2}-r_{1}}\right] \\
& m_{2}=\frac{1}{b_{2}}\left[\frac{r_{2}+a}{r_{2}-r_{1}}\right]
\end{aligned}
$$

Sola Çarpık Tip VI dağılımlarında $K$ normalizasyon sabiti Eşitlik (25)' de verilmektedir.

$$
K=\frac{1}{B\left(m_{1}+1 ;-m_{1}-m_{2}-1\right)\left(r_{2}-r_{1}\right)^{m_{1}+m_{2}+1}}
$$

\section{3.Ön bilgi ile Pearson Tip I-B Dağılımının Belirlenmesi}

$\mathrm{Bu}$ çalışmada orijinal ölçekler için $M, R_{1}$ ve $R_{2}$ sırasıyla modu, alt limiti ve üst limiti göstermektedir. $\quad \mu_{1}^{\prime}=0$ olduğunda Eşitlik (7)' deki $a=-b_{1}$ olarak elde edilecektir. Çalışmada sadece B biçimli dağılımlar analiz edilmektedir. Bu bağlamda dört moment bilgisinin yerine $\mu_{1}^{\prime}$, mod, alt limit ve üst limit kullanılarak dağılım belirlenebilir. Tip I-B dağılımı ön bilgi ile elde edilirken yukarıdaki bilgilere ek olarak sadece birinci moment bilgisi gereklidir. Birinci moment bilgisi mevcut olduğunda çalışma merkezlenmiş değişkenler kullanılarak gerçekleştirilebilir. Örneğin $x$ rassal değişkeni olmak üzere ortalama orijine çekildiğinde payda fonksiyonunun kökleri $r_{1}=R_{1}-\mu_{1}^{\prime}$ ve $-r_{2}=R_{2}-\mu_{1}^{\prime}$ ve $m=M-\mu_{1}^{\prime}$ 's şeklinde ifade edilebilir.

Ön bilgi tarafından Tip I-B dağılımını belirlemek için Eşitlik (12-13) kullanarak $b_{2}$ aşağıdaki gibi elde edilir.

$$
b_{2}=\frac{a}{r_{1}-r_{2}}
$$

Eşitlik (12-13) kullanarak $r_{2}$ ' den $r_{1}^{\prime}$ i çıkararak ve Eşitlik (26)' dan elde edilen $b_{2}$ kullanılarak, $b_{0}$ aşağıdaki gibi hesaplanır.

$$
b_{0}=-\frac{a r_{1} r_{2}}{r_{1}-r_{2}}
$$


Eşitlik (26-27)'den elde edilen sonuçlar Eşitlik (8-9-10)'da yerine koyulduğunda $\mu_{2}, \mu_{3}$ ve $\mu_{4}$ aşağıdaki gibi hesaplanabilir.

$$
\begin{aligned}
& \mu_{2}=\frac{-b_{0}}{3 b_{2}+1} \\
& \mu_{3}=\frac{2 a \mu_{2}}{4 b_{2}+1} \\
& \mu_{4}=\frac{3\left(a \mu_{3}-b_{0} \mu_{2}\right)}{5 b_{2}+1} .
\end{aligned}
$$

Tip I-B dağılımının belirlenmesi aşamasında $b_{1}$ yerine mod bilgisi, $b_{0}$ ve $b_{2}$ yerine de kökler (alt ve üst limit bilgisi) kullanılmaktadır.

\section{4.Ön Bilgi ile Pearson Tip VI B Dağılımının Belirlenmesi}

Pearson Tip VI-B dağılımlarında ön bilgi olarak birinci ve ikinci moment (ortalama ve varyans) bilgilerine ihtiyaç duyulmaktadır. Bu bağlamda,

$$
\begin{aligned}
& m=(M-\mu) / \sigma \\
& r_{1}=\left(R_{1}-\mu\right) / \sigma \\
& r_{2}=\left(R_{2}-\mu\right) / \sigma
\end{aligned}
$$

şeklinde ifade edilebilir. Eşitlik (31-32-33)'deki $\mu$ ve $\sigma$ parametreleri veri setinden hesaplanmaktadır. Ayrıca merkezlenmiş ya da standart değişkenler ile hesaplamalar yapıldığında Tip VI dağılımına ait kökler aynı işaretli olacaktır. Bu tip rassal değişkenler için sağa çarpık Pearson Tip VI B-biçimli dağılımlara ait parametrelerin işaretleri, $b_{0}<0, b_{2}<0, b_{1}<0$ ' dir. Standartlaştırılmış rassal değişken için Eşitlik (8)'de ilgili hesaplamalar yapıldığında,

$$
b_{0}=-\left(1+3 b_{2}\right)
$$

elde edilir. Eşitlik (34) kullanılarak,

$$
-1<b_{0}<0
$$

aralığ 1 elde edilir.

Eşitlik (8) ve Eşitlik (34)' ten yararlanılarak sağa çarpık Pearson Tip VI B-biçimli dağılımların parametreleri aşağıdaki gibi elde edilir. 
$b_{2}=\frac{1-a r_{2}}{r_{2}^{2}-3}$

$b_{0}$ parametresini elde etmek için $b_{2}$ değeri Eşitlik (34)' de yerine konulur. $\mu_{2}=1$ için Eşitlik (9-10)'dan yararlanılarak moment değerleri hesaplanır. Böylece sağa çarpık Tip VI-B dağılımı elde edilir.

Sola çarpık Tip VI-B biçimli dağılımların parametreleri de aynı şekilde merkezlenmiş ya da standart rassal değişkenler için ilave olarak ilk iki moment bilgisinden yararlanılarak hesaplanmaktadır. Burada parametrelerin işaretleri $b_{0}<0, \quad b_{2}<0, b_{1}>0$ 'dir. Parametre, alt sınır ve mod değerinin Eşitlik (7) ve Eşitlik (34)'de yerine koyulması ile Eşitlik (37)'deki şekliyle elde edilir.

$$
b_{2}=\frac{1+a r_{1}}{r_{1}^{2}-3}
$$

$b_{0}$ parametresi $b_{2}$ değeri Eşitlik (34)' de yerine koyularak sağa çarpık duruma benzer şekilde elde edilir. $\mu_{2}=1$ için Eşitlik (9-10) kullanılarak moment değerleri hesaplanır ve böylelikle sola çarpık Tip VI-B dağılımı belirlenebilir (Dündar ve Şehirlioğlu, 2014, s. 49).

\section{Materyal ve Yöntem}

Çalışmada asimetrik toleransa sahip ve asimetrik ya da simetrik dağılım gösteren süreçlerin yeteneğini ölçmek için önerilen indeks aşağıdaki gibidir:

$$
C_{p a c}=\min \left\{\left[\frac{U S L-m}{U-m}\right]\left[1-\frac{|m-T|}{U S L-L S L}\right]\left[1-\frac{\left|\mu_{3}-m_{3}\right|}{(U S L-L S L)^{3}}\right]\left[\frac{B_{2}}{\beta_{2}}\right] ;\left[\frac{m-L S L}{m-L}\right]\left[1-\frac{|m-T|}{U S L-L S L}\right]\left[1-\frac{\left|\mu_{3}-m_{3}\right|}{(U S L-L S L)^{3}}\right]\left[\frac{B_{2}}{\beta_{2}}\right]\right\}
$$

Burada;

$m=$ Proses dağılımının modu

$\mathrm{T}=$ Kalite karakteristiğinin hedef değeri

USL $=$ Kalite karakteristiğinin üst spesifikasyon limiti $\left(r_{1}\right)$

$\mathrm{LSL}=$ Kalite karakteristiğinin alt spesifikasyon limiti $\left(r_{2}\right)$

$\mathrm{U}=$ Proses dağılışının üst sınır değeri. Dağılım sağ taraftan sınırlı ise $r_{1}$, sağ taraftan sinırsiz ise $X_{0,99865}$ alınır. 
$\mathrm{L}=$ Proses dağılışının alt sınır değeri. Dağılım sol taraftan sınırlı ise $r_{2}$, sol taraftan sinırsız ise $\mathrm{X}_{0,00135}$ alınır.

$\mu_{3}=$ Baz dağılımın çarpıklık değeri

$m_{3}=$ Proses dağılımının çarpıklık değeri

$\beta_{2}=$ Baz dağılımın basıklık değeri

$B_{2}=$ Proses dağılımının basıklık değeri

$\mathrm{Bu}$ indeks ile amaçlanan, proses verilerinin dağılımı ile baz dağılımı kıyaslanmasıdır. İndeks bölümler halinde incelendiğinde;

i. $\left[\frac{U S L-m}{U-m}\right]$ ifadesi proses dağılışın sağ tarafının (modun sağındaki kısım) üst spesifikasyon limitinin ne kadar içinde (ya da dişında) olduğunun birimden bağımsız bir ölçüsünü vermektedir. Formülün bu bileşeninde baz dağılımın üst spesifikasyon limiti ile mod değeri arasındaki uzaklık, proses dağılımının üst sınırı ile modu arasındaki uzaklığa oranlanmaktadır. Bu oran büyüdükçe süreç yetenek indeks değeri de artacaktır. Diğer bir deyişle prosesin sağ tarafındaki yayılma azaldıkça ve uzaklaştıkça indeks değeri artacaktır. Aynı şekilde $\left[\frac{m-L S L}{m-L}\right]$ ifadesi baz dağılımın alt spesifikasyon limiti ile hedef değer arasındaki uzaklık, proses dağılımın alt sınırı ile modu arasındaki uzaklığa oranlanmaktadır. Bu oran büyüdükçe süreç yetenek indeks değeri de artacaktır.

ii. $\left[1-\frac{|m-T|}{U S L-L S L}\right]$ ifadesi proses dağılımın modunun, baz dağılımın hedef değerine yakın olmasının, indeks değerini arttıracağı görülmektedir.

iii. $\left[1-\frac{\left|\mu_{3}-m_{3}\right|}{(U S L-L S L)^{3}}\right]$ ifadesi ile çarpıklık değerindeki değişim indeks değerinde azalmaya neden olacağından, süreç yetenek indeks değerini küçültmeye yönelik bir bileşen olarak düşünülmüştür. Çarpıklık değerinin büyümesi, hiçbir zaman istenmeyeceği için, çarpıklık değerindeki oluşan fark mutlak değerce incelenmelidir.

iv. $\left[\frac{B_{2}}{\beta_{2}}\right]$ ifadesi, proses dağılımın basıklık değeri baz dağılımının basıklık değerine göre oranlanmaktadır. Basıklık değeri arttıkça süreç yetenek indeks değerinin de artmasına neden olacaktır. 
Sürecin ürettiği verilerin dağılımı (proses dağılım) ile baz dağılım aynı parametrelere sahip ise, diğer bir deyişle her iki dağılım aynı ise, süreç yetenek indeksi her zaman 1 değerini alacaktır.

Önerilen indeks $C_{p a c}$ için kullanıcılara aşağıda bir prosedür sunulmuştur:

1. İlk olarak ürünün kalite karakteristikleri için belirlenen USL, LSL, T ve $\mu$ değerleri ile baz dağılım olan Pearson Tip I dağılımının parametreleri $\left(b_{0}, b_{1}, b_{2}\right)$ elde edilir. Eğer $\mu$ değeri bilinmiyorsa sola çarpık durumlar için $\mathrm{T}>\mu>(\mathrm{LSL}+\mathrm{USL}) / 2$ koşuluna göre, sağa çarpık durumlar için ise $\mathrm{T}<\mu<(\mathrm{LSL}+\mathrm{USL}) / 2$ koşuluna göre uygun bir ortalama değeri alınır. Bu parametreler ile baz dağılımın ilk dört momenti ve $\beta_{2}$ değeri hesaplanır.

2. Üretim sürecinden alınan örnek verileri ile proses dağılımın üst sınır değeri, alt sınır değeri ve mod değeri belirlenir. Ardından ilk dört moment ve $\mathrm{B}_{2}$ değeri hesaplanır.

3. $\quad C_{p a c}$ indeksinde değerler yerine koyulur ve proses dağılım ile baz dağılım arasında ilgili bileşenler ile bir karşılaştırma yapılır.

Aşağıdaki durumlar için önerilen indeks $C_{p a c}$ ile sürecin yeteneği hakkında yorum yapilabilir:

○ $C_{p a c}<0$ ise proses dağılımın modu spesifikasyon limitlerinin dışında yer almaktadır.

○ $C_{p a c}=0$ ise proses dağılımın modu ile spesifikasyon limitleri aynı değeri almaktadır. Yani proses dağılımın modu üst ya da alt spesifikasyon limitlerinin üzerinde oluşmuştur.

○ $0<C_{p a c}<1$ ise proses dağılımın sınır değerleri tolerans limitlerinin dışında yer almaktadir.

○ $C_{p a c}=1$ ise proses dağılım ile baz dağılım birbirine eştir.

○ $C_{p a c}>1$ ise proses dağılımın sınır değerleri baz dağılımın tolerans limitlerinin içinde yer almakta ve veriler daha fazla hedef değer etrafında toplanmaktadır.

Bu çalışmada indeksin performansını göstermek için aşağıdaki USL, LSL, T ve $\bmod <\mu<\mathrm{L}+\mathrm{U} / 2$ olacak şekilde ortalama $\mu=80$ olan bir baz dağılım seçilmiştir. Baz dağılımın ve örneklerin $C_{p a c}$ indeksinin bileşen sonuçları EK 1' de ayrıntılı olarak verilmiştir. Örnek uygulamalar için MATLAB istatistik paket programı kullanılmıştır. 


\section{Araştırma Bulguları}

Çalışmanın bu kısmında baz dağılım temel alınarak üretim süreçlerinde gerçekleşebilecek sağa çarpık durumlar örneklerle incelenmektedir. Proses dağılımların sınırlarında, mod değerinde, çarpıklık ve basıklık değerlerinde oluşacak değişimlerin indeks üzerinde nasıl bir etkisi olduğu ayrıntılı bir şekilde ele alınmaktadır. Öncelikle aşağıdaki gibi bir baz dağılımın tanımlanmış olduğu varsayılmaktadır.

Baz Dağılım: USL $=100, \mathrm{~T}=75, \mathrm{LSL}=70$ olan ve $\mathrm{T}<\mu<\mathrm{ASL}+\mathrm{LSL} / 2$ olacak şekilde ortalama $\mu=80$ olan bir baz dağılım öngörülmektedir. Ön bilgi ile Pearson Tip I dağılımına sahip olan sürecin ilgili parametreleri aşağıdaki gibidir:

Tablo 2: Pearson Tip I Dağılımına Sahip Baz Dağılımının Parametre Değerleri

\begin{tabular}{|c|c|c|c|c|c|c|}
\hline $\mathbf{r}_{\mathbf{1}}$ & $\mathbf{m}$ & $-\mathbf{r}_{\mathbf{2}}$ & $\mathbf{a}$ & $\mathbf{b}_{\mathbf{0}}$ & $\mathbf{b}_{\mathbf{1}}$ & $\mathbf{b}_{\mathbf{2}}$ \\
\hline 20 & -5 & -10 & 5 & -100 & -5 & 0,5 \\
\hline
\end{tabular}

\begin{tabular}{|c|c|c|c|c|c|c|c|}
\hline $\mathbf{m}_{\mathbf{1}}$ & $\mathbf{m}_{\mathbf{2}}$ & $\mathbf{K}$ & $\boldsymbol{\mu}_{\mathbf{2}}$ & $\boldsymbol{\mu}_{\mathbf{3}}$ & $\boldsymbol{\mu}_{\mathbf{4}}$ & $\boldsymbol{\beta}_{\mathbf{1}}$ & $\boldsymbol{\beta}_{\mathbf{2}}$ \\
\hline 1,667 & 0,333 & 1,6542 & 40 & 133,3333 & 4000 & 0,277778 & 2,5 \\
\hline
\end{tabular}

Elde edilen parametreler çerçevesinde Eşitlik (14)' deki Pearson Tip I olasılık yoğunluk fonksiyonu aşağıdaki gibi elde edilir.

$$
f(x)=1.6542 E-04 *(20-x)^{1.667}(x+10)^{0.333} \quad-10<x<20
$$

Baz dağılımın olasılık yoğunluk fonksiyonu aşağıda gösterilmiştir:

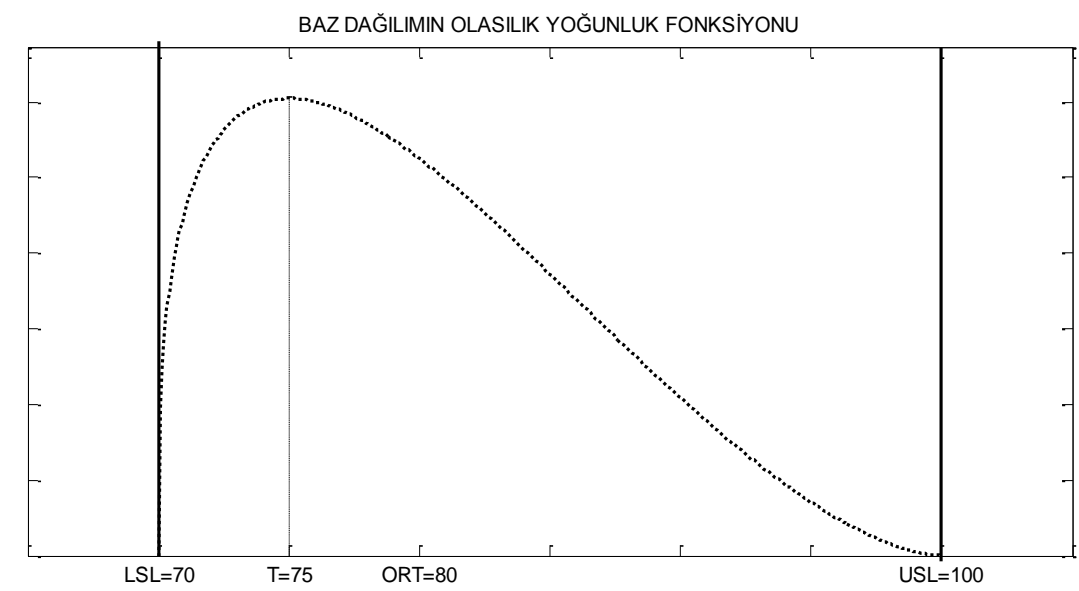

Şekil 1: Baz Dağılımın Olasılık Yoğunluk Fonksiyonu 
Şekil 1'den de görüleceği üzere varsayılan baz dağılım asimetrik toleransa ve asimetrik dağılıma sahip sağa çarpık bir dağılımdır. Yeni indekste, değerleri formüle uyguladığımızda $C_{p a c}$ değeri 1 olur yani baz dağılımının süreç yetenek indeksi 1' dir. Baz dağılımı belirledikten sonra çeşitli durumlar karşısında öne sürülen indeksin performansını gözlemlemek için aşağıda örnekler sunulmuştur.

Örnek 1: $\mathrm{U}=98, \bmod =75, \mathrm{~L}=70$ olan ve $\bmod <\mu<\mathrm{L}+\mathrm{U} / 2$ olacak şekilde ortalama $\mu=80$ olan bir dağılım öngörülmektedir. Pearson Tip I dağılımına sahip olan sürecin ilgili parametreleri aşağıdaki gibidir:

Tablo 3: Örnek 1' e Ait Gerçekleşen Dağılımının Parametre Değerleri

\begin{tabular}{|l|l|l|l|l|l|l|}
\hline $\mathbf{r}_{\mathbf{1}}$ & $\mathbf{m}$ & $-\mathbf{r}_{\mathbf{2}}$ & $\mathbf{a}$ & $\mathbf{b}_{\mathbf{0}}$ & $\mathbf{b}_{\mathbf{1}}$ & $\mathbf{b}_{\mathbf{2}}$ \\
\hline 18 & -5 & -10 & 5 & $-112,5$ & -5 & 0,625 \\
\hline
\end{tabular}

\begin{tabular}{|l|l|l|l|l|l|l|l|}
\hline $\mathbf{m}_{\mathbf{1}}$ & $\mathbf{m}_{\mathbf{2}}$ & $\mathbf{K}$ & $\boldsymbol{\mu}_{\mathbf{2}}$ & $\boldsymbol{\mu}_{\mathbf{3}}$ & $\boldsymbol{\mu}_{\mathbf{4}}$ & $\boldsymbol{\beta}_{\mathbf{1}}$ & $\boldsymbol{\beta}_{\mathbf{2}}$ \\
\hline 1,314 & 0,286 & $6,0653 \mathrm{E}-04$ & 39,1304 & 111,8012 & 3608,131 & 0,208617 & 2,356421 \\
\hline
\end{tabular}

Elde edilen parametreler çerçevesinde Pearson Tip I olasılık yoğunluk fonksiyonu aşağıdaki formülden elde edilir.

$$
f(x)=6.0653 \mathrm{E}-04 *(18-x)^{1.314}(x+10)^{0.286} \quad-10<x<18
$$

Ayrıca proses dağılım ile baz dağılımın ortak grafiksel gösterimi Şekil 2' de gösterilmiştir.

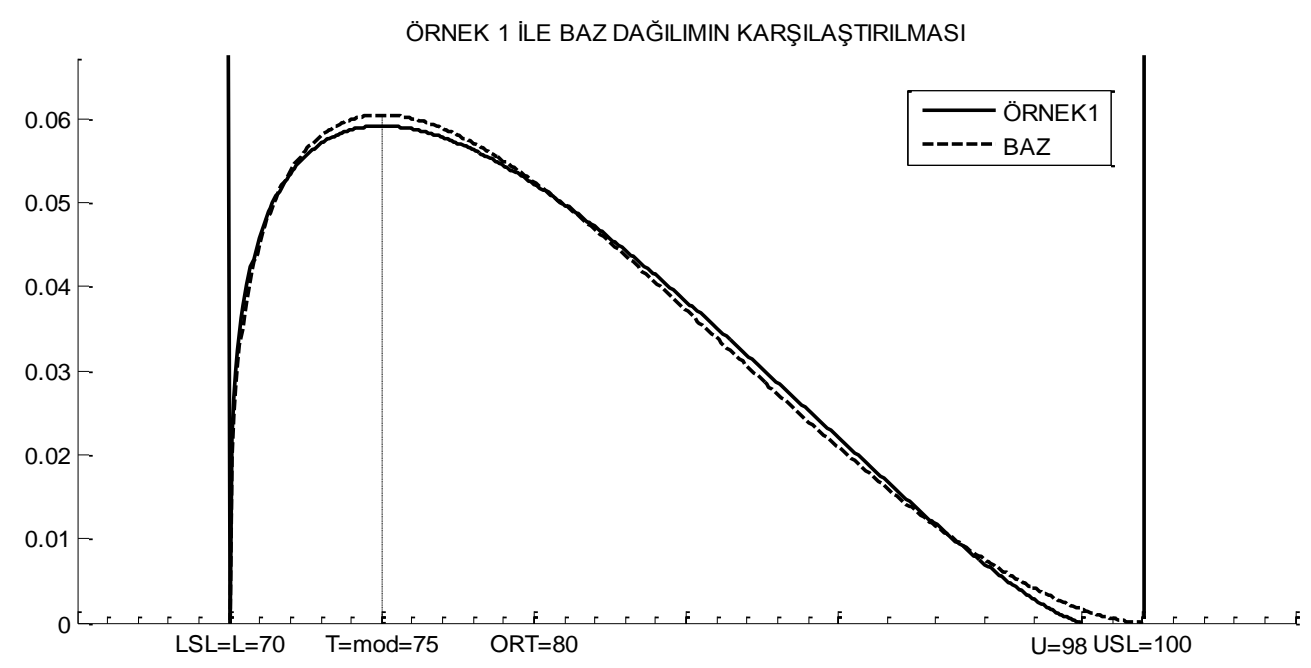

Şekil 2: Örnek 1 İçin Gerçekleşen (Proses) Dağılım ile Baz Dağılımın Karşılaştırılması 
Yeni indekste değerler yerine koyulduğunda $C_{p a c}$ değeri 0,942 bulunmuştur.

Örnek 1' de görüleceği gibi proses dağ 1 lımın olasılık yoğunluk fonksiyonunu baz dağılımın olasılık yoğunluk fonksiyonuna göre basıklık ve çarpıklık değeri daha düşüktür. $\mathrm{Bu}$ da verilerin hedef değer etrafında toplanmaktan uzaklaştığını göstermekte ve bu bileşenin indeks değerinde negatif bir etki sağlamaktadır. L sabit kalmakla birlikte $\mathrm{U}$ değeri limitlerden daha içeride gerçekleşmiştir. $\mathrm{Bu}$ da indeks bileşeninde pozitif yönde bir katkı sağlamaktadır. Aynı şekilde mod değerinde bir değişiklik olmadığı için indeks bileşeninde 1 değerini alarak olumlu ya da olumsuz bir etkisi olmayacaktır. Proses dağılımın çarpıklık değerindeki azalma indeksi değerini de azaltmaktadır. Proses dağılım baz dağılımına göre daha düşük bir süreç yeteneğine sahiptir.

Örnek 2: $\mathrm{U}=98, \bmod =75, \mathrm{~L}=72$ olan ve $\bmod <\mu<\mathrm{L}+\mathrm{U} / 2$ olacak şekilde ortalama $\mu=80$ olan bir dağılım öngörülmektedir. Pearson Tip I dağılımına sahip olan sürecin ilgili parametreleri aşağıdaki gibidir.

Tablo 4: Örnek 2’e Ait Proses Dağılımının Parametre Değerleri

\begin{tabular}{|l|l|l|l|l|l|l|}
\hline $\mathbf{r}_{\mathbf{1}}$ & $\mathbf{m}$ & $-\mathbf{r}_{\mathbf{2}}$ & $\mathbf{a}$ & $\mathbf{b}_{\mathbf{0}}$ & $\mathbf{b}_{\mathbf{1}}$ & $\mathbf{b}_{\mathbf{2}}$ \\
\hline 18 & -5 & -8 & 5 & -72 & -5 & 0,5 \\
\hline
\end{tabular}

\begin{tabular}{|l|l|l|l|l|l|l|l|}
\hline $\mathbf{m}_{\mathbf{1}}$ & $\mathbf{m}_{\mathbf{2}}$ & $\mathbf{K}$ & $\boldsymbol{\mu}_{\mathbf{2}}$ & $\boldsymbol{\mu}_{\mathbf{3}}$ & $\boldsymbol{\mu}_{\mathbf{4}}$ & $\boldsymbol{\beta}_{\mathbf{1}}$ & $\boldsymbol{\beta}_{\mathbf{2}}$ \\
\hline 1,769 & 0,231 & $2,2951 \mathrm{E}-04$ & 28,8 & 96 & 2188,8 & 0,385802 & 2,638889 \\
\hline
\end{tabular}

Elde edilen parametreler çerçevesinde Pearson Tip I olasılık yoğunluk fonksiyonu aşağıdaki formülden elde edilir.

$$
f(x)=2.2951 \mathrm{E}-04 *(18-x)^{1.769}(x+8)^{0.231} \quad-8<x<18
$$

Ayrıca proses dağılım ile baz dağglımın ortak grafiksel gösterimi Şekil 3' de gösterilmiştir. 


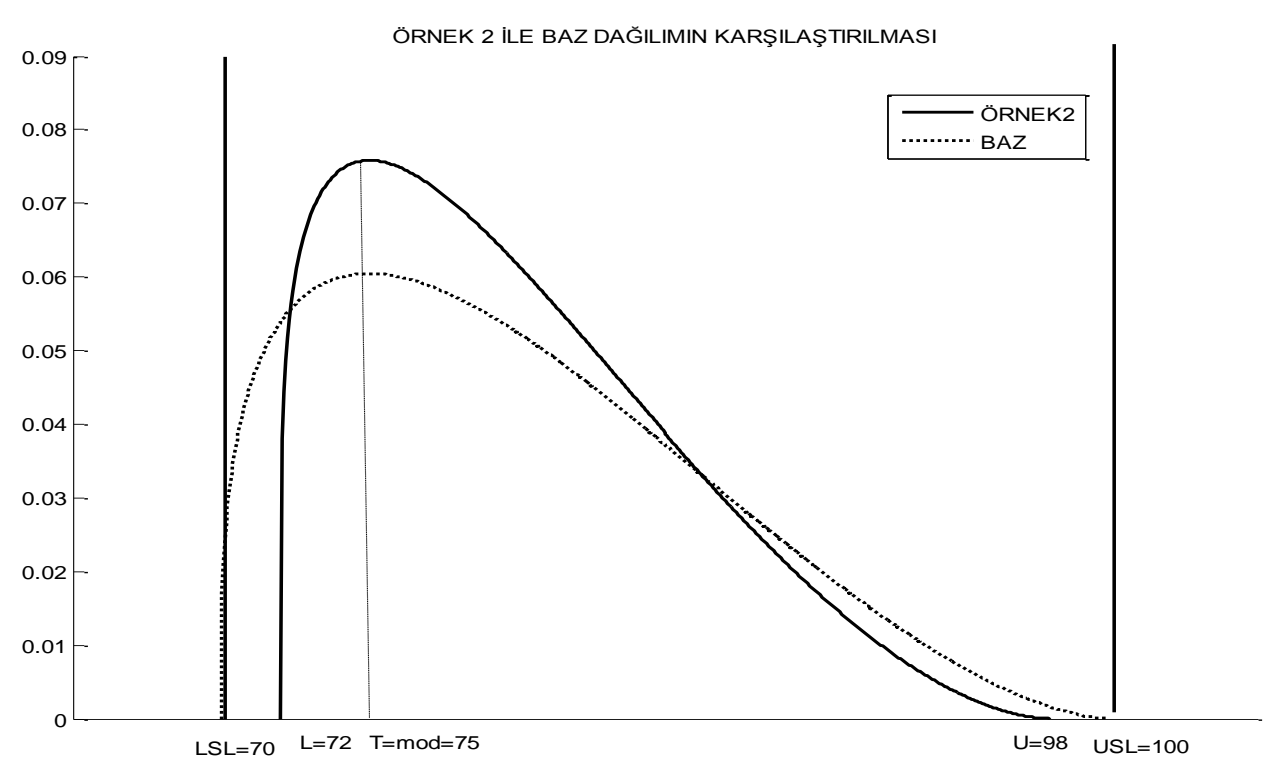

\section{Şekil 3: Örnek 2 İçin Proses Dağılım ile Baz Dağılımın Karşılaştırılması}

Yeni indekste değerler yerine koyulduğunda $C_{p a c}$ değeri 1,146 bulunmuştur.

Örnek 2'de U ve L değeri daha limitlerin içindedir. Yani proses süreçte tüm veriler tolerans limitlerinin içindedir. Proses dağılımın çarpıklık değerindeki azalma indeksi değerini de azaltmaktadır. Ancak U, L ve basıklık değerinde görülen iyileşme çarpıklıkta oluşan azalmayı bertaraf etmiştir. Proses dağılım baz dağılımına göre daha iyi bir süreç yeteneğine sahiptir.

Örnek 3: $\mathrm{U}=100, \bmod =75, \mathrm{~L}=72$ olan ve $\bmod <\mu<\mathrm{L}+\mathrm{U} / 2$ olacak şekilde ortalama $\mu=80$ olan bir dağılım öngörülmektedir. Pearson Tip I dağılımına sahip olan sürecin ilgili parametreleri aşağıdaki gibidir.

Tablo 5: Örnek 3' e Ait Proses Dağılımının Parametre Değerleri

\begin{tabular}{|l|l|l|l|l|l|l|}
\hline $\mathbf{r}_{\mathbf{1}}$ & $\mathbf{m}$ & $-\mathbf{r}_{\mathbf{2}}$ & $\mathbf{a}$ & $\mathbf{b}_{\mathbf{0}}$ & $\mathbf{b}_{\mathbf{1}}$ & $\mathbf{b}_{\mathbf{2}}$ \\
\hline 20 & -5 & -8 & 5 & $-66,6667$ & -5 & 0,416667 \\
\hline
\end{tabular}

\begin{tabular}{|l|l|l|l|l|l|l|l|}
\hline $\mathbf{m}_{\mathbf{1}}$ & $\mathbf{m}_{\mathbf{2}}$ & $\mathbf{K}$ & $\boldsymbol{\mu}_{\mathbf{2}}$ & $\boldsymbol{\mu}_{\mathbf{3}}$ & $\boldsymbol{\mu}_{\mathbf{4}}$ & $\boldsymbol{\beta}_{\mathbf{1}}$ & $\boldsymbol{\beta}_{\mathbf{2}}$ \\
\hline 2,1429 & 0,2571 & 5,8745 & 29,6296 & 111,1111 & 2462,462 & 0,474609 & 2,804899 \\
\hline
\end{tabular}

Elde edilen parametreler çerçevesinde Pearson Tip I olasılık yoğunluk fonksiyonu aşağıdaki formülden elde edilir. 


$$
f(x)=5.8745 \mathrm{E}-05^{*}(20-x)^{2.1429}(x+8)^{0.2571} \quad-8<x<20
$$

Ayrıca proses dağılım ile baz dağılımın ortak grafiksel gösterimi Şekil 4' de gösterilmiştir.

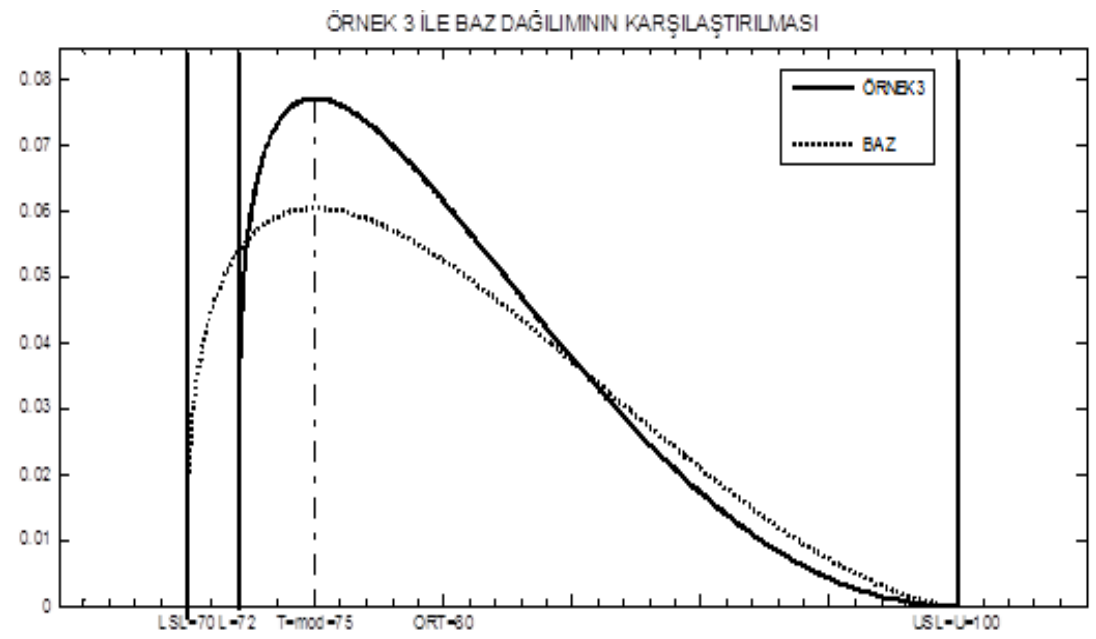

\section{Şekil 4: Örnek 3 İçin Proses Dağılım ile Baz Dağılımın Karşılaştırılması}

Yeni indekste değerler yerine koyulduğunda $C_{p a c}$ değeri 1,121 bulunmuştur.

Örnek 3'de U değeri sabit bırakılıp L değeri hedef değere yaklaştırılmıştır. Proses dağılımda verilerin tamamı tolerans limitlerinin içindedir. Proses dağılımın çarpıklık değerindeki azalma indeksi değerini de azaltmaktadır. Ancak L ve basıklık değerinde görülen iyileşme çarpıklıkta oluşan azalmaya rağmen indeks değerini arttırmıştır. Proses dağılım baz dağılımına göre daha iyi bir süreç yeteneğine sahiptir.

Örnek 4: $\mathrm{U}=110, \bmod =75, \mathrm{~L}=70$ olan ve $\bmod <\mu<\mathrm{L}+\mathrm{U} / 2$ olacak şekilde ortalama $\mu=80$ olan bir dağılım öngörülmektedir. Pearson Tip I dağılımına sahip olan sürecin ilgili parametreleri aşağıdaki gibidir.

Tablo 6: Örnek 4' e Ait Proses Dağılımının Parametre Değerleri

\begin{tabular}{|l|l|l|l|l|l|l|}
\hline $\mathbf{r}_{\mathbf{1}}$ & $\mathbf{m}$ & $-\mathbf{r}_{\mathbf{2}}$ & $\mathbf{a}$ & $\mathbf{b}_{\mathbf{0}}$ & $\mathbf{b}_{\mathbf{1}}$ & $\mathbf{b}_{\mathbf{2}}$ \\
\hline 30 & -5 & -10 & 5 & -75 & -5 & 0,25 \\
\hline
\end{tabular}

\begin{tabular}{|l|l|l|l|l|l|l|l|}
\hline $\mathbf{m}_{\mathbf{1}}$ & $\mathbf{m}_{\mathbf{2}}$ & $\mathbf{K}$ & $\boldsymbol{\mu}_{\mathbf{2}}$ & $\boldsymbol{\mu}_{\mathbf{3}}$ & $\boldsymbol{\mu}_{\mathbf{4}}$ & $\boldsymbol{\beta}_{\mathbf{1}}$ & $\boldsymbol{\beta}_{\mathbf{2}}$ \\
\hline 3,5 & 0,5 & $1,13686 \mathrm{E}-07$ & 42,8571 & 214,2857 & 5714,286 & 0,5833 & 3,111 \\
\hline
\end{tabular}


Elde edilen parametreler çerçevesinde Pearson Tip I olasılık yoğunluk fonksiyonu aşağıdaki formülden elde edilir.

$$
f(x)=1.13686 \mathrm{E}-07 *(30-x)^{3.5}(x+10)^{0.5} \quad-10<x<30
$$

Ayrıca proses dağılım ile baz dağılımın ortak grafiksel gösterimi Şekil 5' de gösterilmiştir.

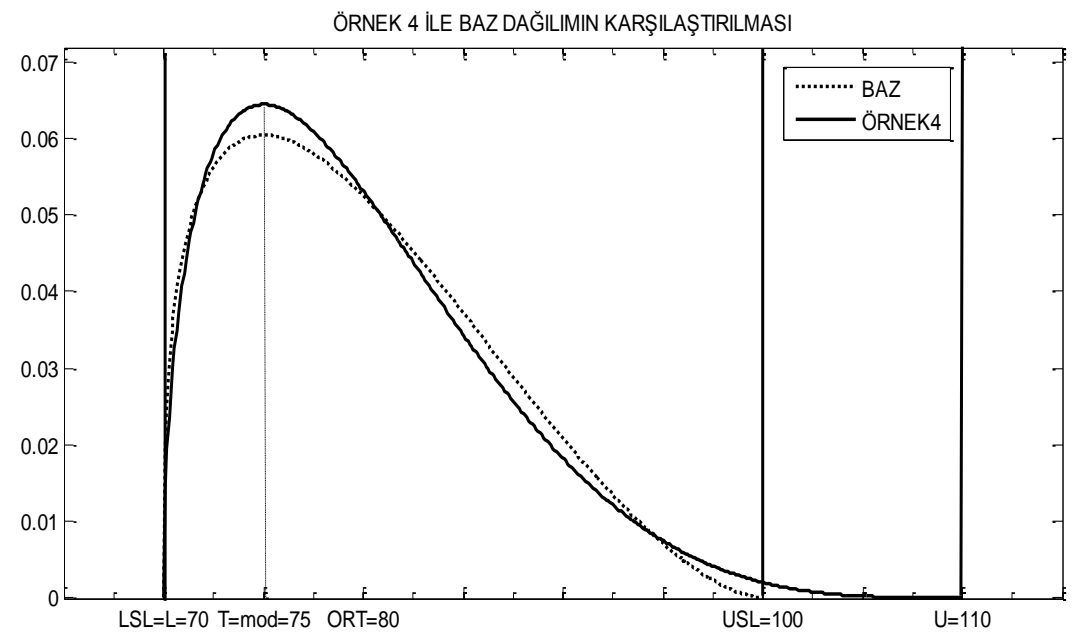

\section{Şekil 5: Örnek 4 İçin Proses Dağılım ile Baz Dağılımın Karşılaştırılması}

Yeni indekste değerler yerine koyulduğunda $C_{p a c}$ değeri 0,886 bulunmuştur.

Örnek 4' de L değeri sabit bırakılıp U değeri baz dağılımın USL limitinin dışında gerçekleşmektedir. Proses dağılımda verilerin bir kısmı tolerans limitinin dışındadır. Proses dağılımın olasılık yoğunluk fonksiyonu baz dağılımın olasılık yoğunluk fonksiyonuna göre daha çok basıktır. U değeri limitin dışına çıktığı için indekse negatif yansımaktadır. Proses dağılımın çarpıklık değerindeki azalma indeksi değerini de azaltmaktadır. Proses dağılım baz dağılımına göre daha kötü bir süreç yeteneğine sahiptir.

Örnek 5: $\mathrm{U}=100, \bmod =75, \mathrm{~L}=68$ olan ve $\bmod <\mu<\mathrm{L}+\mathrm{U} / 2$ olacak şekilde ortalama $\mu=80$ olan bir dağılımı öngörülmektedir. Pearson Tip I dağılımına sahip olan sürecin ilgili parametreleri aşağıdaki gibidir: 
Tablo 7: Örnek 5' e Ait Proses Dağılımının Parametre Değerleri

\begin{tabular}{|l|l|l|l|l|l|l|}
\hline $\mathbf{r}_{\mathbf{1}}$ & $\mathbf{m}$ & $-\mathbf{r}_{\mathbf{2}}$ & $\mathbf{a}$ & $\mathbf{b}_{\mathbf{0}}$ & $\mathbf{b}_{\mathbf{1}}$ & $\mathbf{b}_{\mathbf{2}}$ \\
\hline 20 & -5 & -12 & 5 & -150 & -5 & 0,625 \\
\hline
\end{tabular}

\begin{tabular}{|l|l|l|l|l|l|l|l|}
\hline $\mathbf{m}_{\mathbf{1}}$ & $\mathbf{m}_{\mathbf{2}}$ & $\mathbf{K}$ & $\boldsymbol{\mu}_{\mathbf{2}}$ & $\boldsymbol{\mu}_{\mathbf{3}}$ & $\boldsymbol{\mu}_{\mathbf{4}}$ & $\boldsymbol{\beta}_{\mathbf{1}}$ & $\boldsymbol{\beta}_{\mathbf{2}}$ \\
\hline 1,25 & 0,35 & 4,49448867 & 52,1739 & 149,0683 & 6233,766 & 0,156463 & 2,290043 \\
\hline
\end{tabular}

Elde edilen parametreler çerçevesinde Pearson Tip I olasılık yoğunluk fonksiyonu aşağıdaki formülden elde edilir.

$$
f(x)=4.494488678 \mathrm{E}-04 *(20-x)^{1.25}(x+12)^{0.35} \quad-12<x<20
$$

Ayrıca proses dağılım ile baz dağılımın ortak grafiksel gösterimi Şekil 6' da gösterilmiştir.

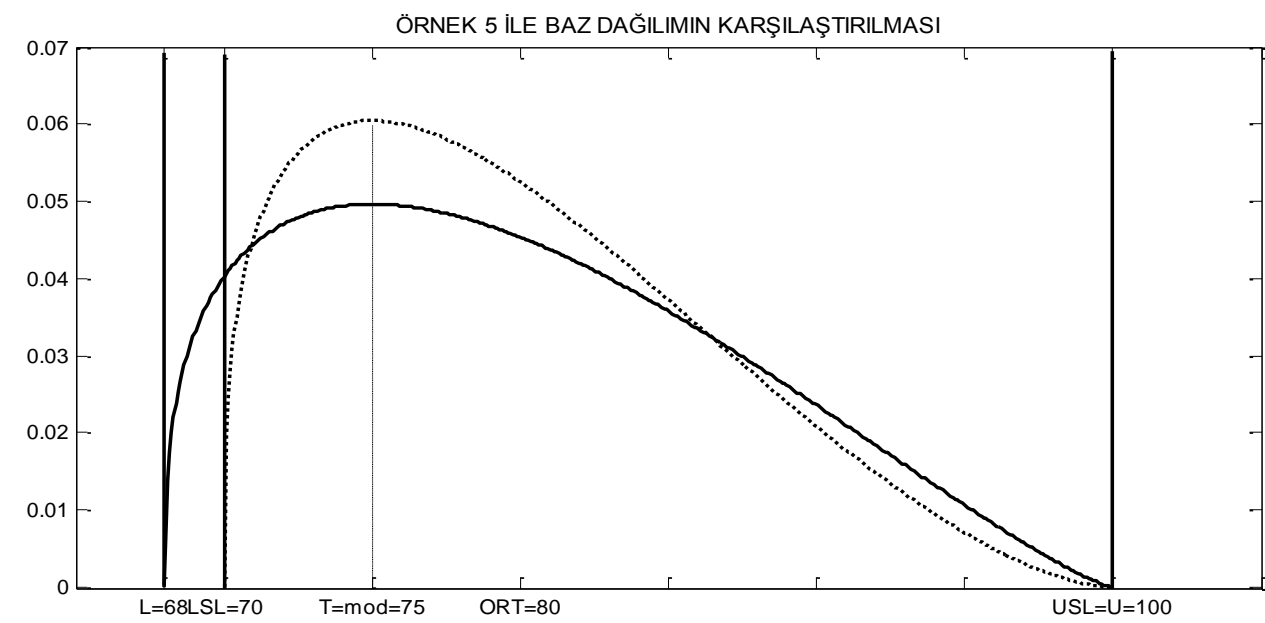

\section{Şekil 6: Örnek 5 İçin Proses Dağılım ile Baz Dağılımın Karşılaştırılması}

Yeni indekste değerler yerine koyulduğunda $C_{p a c}$ değeri 0,654 bulunmuştur.

Örnek 5' de U değeri sabit bırakılıp L değeri baz dağılımın LSL limitinin dışında gerçekleşmektedir. Proses dağılımda verilerin bir kısmı tolerans limitinin dışındadır. L değeri limitin dışına çıktığı için indekse negatif yansımaktadır. Proses dağılımın olasılık yoğunluk fonksiyonu baz dağılımın olasılık yoğunluk fonksiyonuna göre daha az basık olduğu için indeks bileşeni daha küçük çıkmıştır. Proses dağılımın çarpıklık değeri baz dağılımın çarpıklığına göre daha büyüktür ancak baz dağılımının çarpıklık değerinden uzaklaştığı için indeks değerini 
azaltmaktadır. Proses dağılım baz dağılımına göre daha kötü bir süreç yeteneğine sahiptir.

Örnek 6: $\mathrm{U}=102, \bmod =75, \mathrm{~L}=68$ olan ve $\bmod <\mu<\mathrm{L}+\mathrm{U} / 2$ olacak şekilde ortalama $\mu=80$ olan bir dağılım öngörülmektedir. Pearson Tip I dağılımına sahip olan sürecin ilgili parametreleri aşağıdaki gibidir.

Tablo 8: Örnek 6' ya Ait Proses Dağılımının Parametre Değerleri

\begin{tabular}{|l|l|l|l|l|l|l|}
\hline $\mathbf{r}_{\mathbf{1}}$ & $\mathbf{m}$ & $-\mathbf{r}_{\mathbf{2}}$ & $\mathbf{a}$ & $\mathbf{b}_{\mathbf{0}}$ & $\mathbf{b}_{\mathbf{1}}$ & $\mathbf{b}_{\mathbf{2}}$ \\
\hline 22 & -5 & -12 & 5 & -132 & -5 & 0,5 \\
\hline
\end{tabular}

\begin{tabular}{|l|l|l|l|l|l|l|l|}
\hline $\mathbf{m}_{\mathbf{1}}$ & $\mathbf{m}_{\mathbf{2}}$ & $\mathbf{K}$ & $\boldsymbol{\mu}_{\mathbf{2}}$ & $\boldsymbol{\mu}_{\mathbf{3}}$ & $\boldsymbol{\mu}_{\mathbf{4}}$ & $\boldsymbol{\beta}_{\mathbf{1}}$ & $\boldsymbol{\beta}_{\mathbf{2}}$ \\
\hline 1,588 & 0,412 & 1,21502 & 52,8 & 176 & 6728,229 & 0,210438 & 2,41342 \\
\hline
\end{tabular}

Elde edilen parametreler çerçevesinde Pearson Tip I olasılık yoğunluk fonksiyonu aşağıdaki formülden elde edilir.

$$
f(x)=1.2150288 \mathrm{E}-04 *(22-x)^{1.588}(x+12)^{0.412} \quad-12<x<22
$$

Ayrıca proses dağglım ile baz dağılımın ortak grafiksel gösterimi Şekil 7' de gösterilmiştir.

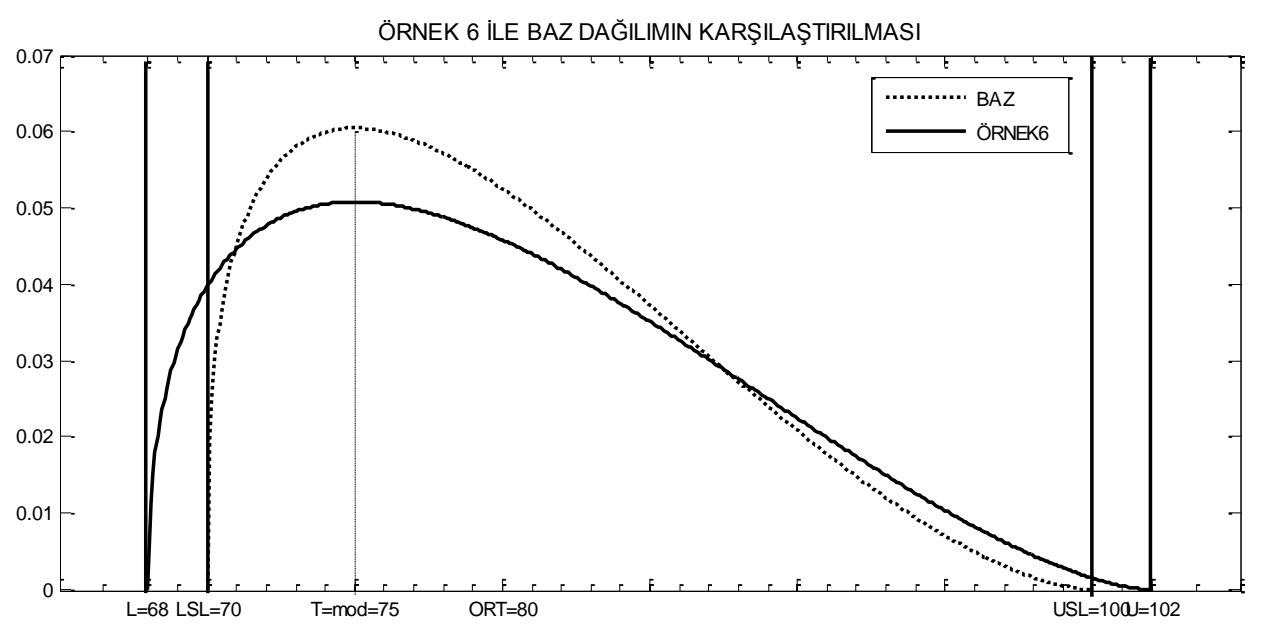

\section{Şekil 7: Örnek 6 İçin Proses Dağılım ile Baz Dağılımın Karşılaştırılması}

Yeni indekste değerler yerine koyulduğunda $C_{p a c}$ değeri 0,602 bulunmuştur. 
Örnek 6' da hem U hem de L değeri baz dağılımın tolerans limitlerinin dişında gerçekleşmektedir. U ve L değerleri limitlerin dışına çıktığı için indekse negatif yansımaktadır. Aynı şekilde mod değerinde bir değişiklik olmadığı için indeks bileşeninde 1 değerini alarak olumlu ya da olumsuz bir etkisi olmamaktadır. Proses dağılımın çarpıklık değeri baz dağılımın çarpıklığına göre daha büyüktür ancak baz dağılımının çarpıklık değerinden uzaklaştığı için indeks değerini azaltmaktadır. Proses dağılım baz dağılımına göre daha kötü bir süreç yeteneğine sahiptir.

Örnek 7: $U=100, \bmod =82, L=55$ olan $v e \bmod >\mu>L+U / 2$ olacak şekilde ortalama $\mu=80$ olan bir dağılım öngörülmektedir. Pearson Tip I sola çarpık dağılımına sahip olan sürecin ilgili parametreleri aşağıdaki gibidir:

Tablo 9: Örnek 7’e Ait Proses Dağılımının Parametre Değerleri

\begin{tabular}{|l|l|l|l|l|l|l|}
\hline $\mathbf{r}_{\mathbf{1}}$ & $\mathbf{m}$ & $-\mathbf{r}_{\mathbf{2}}$ & $\mathbf{a}$ & $\mathbf{b}_{\mathbf{0}}$ & $\mathbf{b}_{\mathbf{1}}$ & $\mathbf{b}_{\mathbf{2}}$ \\
\hline 20 & 2 & -25 & -2 & -200 & 2 & 0,4 \\
\hline
\end{tabular}

\begin{tabular}{|l|l|l|l|l|l|l|l|}
\hline $\mathbf{m}_{\mathbf{1}}$ & $\mathbf{m}_{\mathbf{2}}$ & $\mathbf{K}$ & $\boldsymbol{\mu}_{\mathbf{2}}$ & $\boldsymbol{\mu}_{\mathbf{3}}$ & $\boldsymbol{\mu}_{\mathbf{4}}$ & $\boldsymbol{\beta}_{\mathbf{1}}$ & $\boldsymbol{\beta}_{\mathbf{2}}$ \\
\hline 1 & 1,5 & 1,4312318 & 90,9091 & $-139,86$ & 18461,54 & 0,026036 & 2,233846 \\
\hline
\end{tabular}

Elde edilen parametreler çerçevesinde Pearson Tip I olasılık yoğunluk fonksiyonu aşağıdaki formülden elde edilir.

$$
f(x)=1.4312318 \mathrm{E}-05^{*}(20-x)^{1}(x+25)^{1.5} \quad-25<x<20
$$

Ayrıca proses dağılım ile baz dağılımın ortak grafiksel gösterimi Şekil 8' de gösterilmiştir.

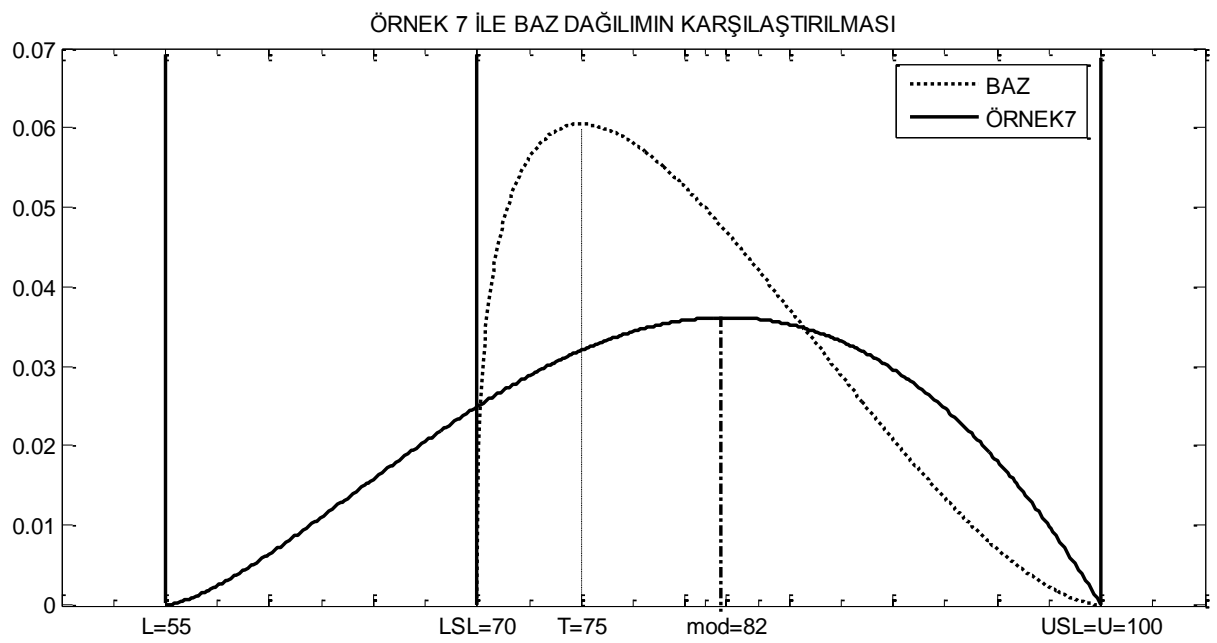

Şekil 8: Örnek 7 İçin Proses Dağılım ile Baz Dağılımın Karşılaştırılması 
Yeni indekste değerler yerine koyulduğunda $C_{p a c}$ değeri 0,301 bulunmuştur.

Örnek 7' de U değeri sabit kalırken mod değeri hedef değerden 2 birimlik bir sapma göstermiştir. L değerleri limitlerin dışına çıktığ 1 için indekse negatif yansımaktadır. Proses dağılımın çarpıklık değeri baz dağılımın çarpıklığına göre daha küçüktür ancak baz dağılımının çarpıklık değerinden uzaklaştığı için indeks değerini azaltmaktadır. Hem mod değerindeki değişim hem de çarpıklık ve basıklık değerlerinden uzaklaşma proses dağılımın baz dağılımına göre daha kötü bir süreç yeteneğine sahip olmasına neden olmuştur.

Örnek 8: $\mathrm{U}=92, \bmod =90, \mathrm{~L}=50$ olan $v e \bmod >\mu>\mathrm{L}+\mathrm{U} / 2$ olacak şekilde ortalama $\mu=80$ olan bir dağılım öngörülmektedir. Pearson Tip I sola çarpık dağılımına sahip olan sürecin ilgili parametreleri aşağıdaki gibidir:

Tablo 11: Örnek 8' e Ait Proses Dağılımının Parametre Değerleri

\begin{tabular}{|l|l|l|l|l|l|l|}
\hline $\mathbf{r}_{\mathbf{1}}$ & $\mathbf{m}$ & $-\mathbf{r}_{\mathbf{2}}$ & $\mathbf{a}$ & $\mathbf{b}_{\mathbf{0}}$ & $\mathbf{b}_{\mathbf{1}}$ & $\mathbf{b}_{\mathbf{2}}$ \\
\hline 12 & 10 & -30 & -10 & -200 & 10 & 0,555556 \\
\hline
\end{tabular}

\begin{tabular}{|l|l|l|l|l|l|l|l|}
\hline $\mathbf{m}_{\mathbf{1}}$ & $\mathbf{m}_{\mathbf{2}}$ & $\mathbf{K}$ & $\boldsymbol{\mu}_{\mathbf{2}}$ & $\boldsymbol{\mu}_{\mathbf{3}}$ & $\boldsymbol{\mu}_{\mathbf{4}}$ & $\boldsymbol{\beta}_{\mathbf{1}}$ & $\boldsymbol{\beta}_{\mathbf{2}}$ \\
\hline 0,086 & 1,714 & $8,94937 \mathrm{E}-05$ & 75 & $-465,517$ & 15608,52 & 0,513674 & 2,774848 \\
\hline
\end{tabular}

Elde edilen parametreler çerçevesinde Pearson Tip I olasılık yoğunluk fonksiyonu aşağıdaki formülden elde edilir.

$$
f(x)=8.94937 \mathrm{E}-05^{*}(12-x)^{0.086}(x+30)^{1.714} \quad-30<x<12
$$

Ayrıca proses dağılım ile baz dağılımın ortak grafiksel gösterimi Şekil 10’ de gösterilmiştir. 


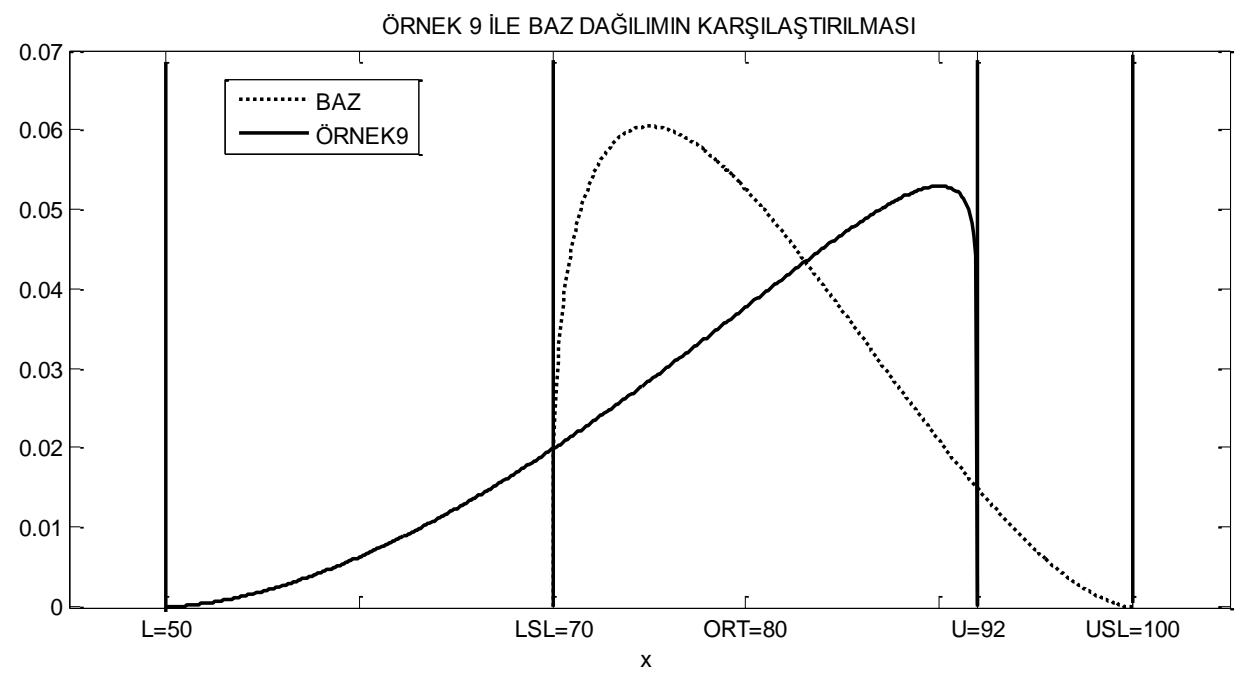

Şekil 10: Örnek 8 İçin Proses Dağılım ile Baz Dağılımın Karşılaştırılması

Yeni indekste değerler yerine koyulduğunda $C_{p a c}$ değeri 0,271 bulunmuştur.

Örnek 8' de mod değeri hedef değerden oldukça uzaklaşmıştır. L değerleri limitlerin dışına çıktığı için indekse negatif yansımaktadır. Proses dağılımın çarpıklık değeri baz dağılımın çarpıklığına göre daha küçüktür ancak baz dağılımının çarpıklık değerinden uzaklaştığı için indeks değerini azaltmaktadır. Hem mod değerindeki değişim hem de çarpıklık ve basıklık değerlerinden uzaklaşma proses dağılımın baz dağılımına göre daha kötü bir süreç yeteneğine sahip olmasina neden olmuştur.

\section{Sonuç}

Bu çalışmanın amacı, literatürde şimdiye kadar çalışılmayan, asimetrik tolerans ve asimetrik dağılıma sahip süreçlerin yeteneğini ölçmek için kullanılabilecek yeni bir indeks önermektir. Önerilen indeks $C_{p a c}$ ile proses dağılımı ile karakteristiğin tolerans limitlerinden elde edilen baz dağılımın karşılaştırılması temel alınarak sürecin yeteneği hakkında yorum yapılabilmektedir. İndeksin değeri, dağılımın hedef değerden uzaklığ 1 , basıklık ve çarpıklık değerlerindeki değişimi ile alt ve üst spesifikasyon limitlerine olan yakınlığı dikkate alınarak elde edilmektedir.

Baz dağılımın üst spesifikasyon limiti ile hedef değer arasındaki uzaklık, proses dağılımın üst sınırı ile modu arasındaki uzaklığa oranlandığında, oran büyüdükçe yani yayılım azaldıkça süreç yetenek indeks değeri artacaktır. Diğer bir deyişle proses dağılım verileri hedef değere yaklaştıkça indekse olumlu bir katkıda bulunacaktır. Ayrıca proses dağılımın modunun, baz dağılımın hedef değerine yakın olması indeks değerini arttırdığı sonucuna varılmaktadır. Çarpıklık değerindeki değişim, indeks değerinde azalmaya neden olacağından, süreç 
yetenek indeks değerini küçültmeye yönelik bir bileşendir. Çarpıklık değerinin büyümesi, hiçbir zaman istenmeyeceği için, çarpıklık değerindeki oluşan fark mutlak değerce incelenmelidir. Proses dağılımın basıklık değeri, baz dağılımının basıklık değerine göre oranlanmaktadır. Basıklık değerinin artması süreç yetenek indeks değerinin de artmasına neden olacaktır.

İndeks, asimetrik toleransa sahip süreçlerde arzu edilen normal olmayan dağılımlar için sürecin yeteneği hakkında bilgi verse de dezavantajı da vardır. $C_{p a c}$ indeksinin dağılış özelliklerinin diğer bir deyiş̧le indeks tahmin edicisinin elde edilmesi için daha fazla çalışma yapılması gerekmektedir.

Bundan sonraki çalışmalarda hedef değerin, spesifikasyon limitlerine eşit olduğu durumlar (örneğin USL $=70, \mathrm{LSL}=50$ ve $\mathrm{T}=70$ gibi.) için indeks geliştirilebilir. $\mathrm{Bu}$ gibi bir durumda istenen baz dağılım J-şeklinde olacaktır ve Pearson dağılım ailesi indeksin performansını ölçmek için kullanılabilir.

\section{Ekler}

EK 1. Örnek Verileri İçin $C_{p a c}$ İndeksini Oluşturan Formüllerin Sayısal Sonuçları

\begin{tabular}{|l|l|l|l|l|l|l|l|l|l|l|l|l|l|l|l|l|}
\hline & $U$ & $\bmod$ & $L$ & $\mu$ & $r_{1}$ & $m$ & $-r_{2}$ & $\mu_{3}$ & $\beta_{2}$ & $\frac{U S L-m}{U-m}$ & {$\left[1-\frac{|m-T|}{U S L-L S L}\right]$} & {$\left[1-\frac{\left|\mu_{3}-m_{3}\right|}{(U S L-L S L)^{3}}\right]\left|\frac{B_{2}}{\beta_{2}}\right|\left[\frac{m-L S L}{m-L}\right] \mid C_{p a c}$} \\
\hline Baz dağ1lım & $100=(U S L)$ & $75=(\mathrm{T})$ & $70=(\mathrm{LSL})$ & 80 & 20 & -5 & -10 & 133,333 & 2,500 & 1,000 & 1,000 & 1 & 0 & 1,000 & 1,000 \\
\hline Örnek1 & 98 & 75 & 70 & 80 & 18 & -5 & -10 & 111,801 & 2,356 & 1,087 & 1,000 & 0,999202515 & 0,943 & 1,000 & $\mathbf{1 , 0 0 0}$ \\
\hline Örnek 2 & 98 & 75 & 72 & 80 & 18 & -5 & -8 & 96,000 & 2,639 & 1,087 & 1,000 & 0,998617284 & 1,056 & 1,667 & $\mathbf{1 , 1 4 6}$ \\
\hline Örnek 3 & 100 & 75 & 72 & 80 & 20 & -5 & -8 & 111,111 & 2,805 & 1,000 & 1,000 & 0,999176955 & 1,122 & 1,667 & $\mathbf{1 , 1 2 1}$ \\
\hline Örnek 4 & 110 & 75 & 70 & 80 & 30 & -5 & -10 & 214,286 & 3,111 & 0,714 & 1,000 & 0,997001764 & 1,244 & 1,000 & $\mathbf{0 , 8 8 6}$ \\
\hline Örnek 5 & 100 & 75 & 68 & 80 & 20 & -5 & -12 & 149,068 & 2,290 & 1,000 & 1,000 & 0,999417223 & 0,916 & 0,714 & $\mathbf{0 , 6 5 4}$ \\
\hline Örnek 6 & 102 & 75 & 67 & 80 & 22 & -5 & -12 & 176,000 & 2,413 & 0,926 & 1,000 & 0,998419753 & 0,965 & 0,625 & $\mathbf{0 , 6 0 2}$ \\
\hline Örnek 7 & 100 & 82 & 55 & 80 & 20 & 2 & -25 & $-139,860$ & 2,234 & 1,389 & 0,767 & 0,989881723 & 0,894 & 0,444 & $\mathbf{0 , 3 0 1}$ \\
\hline Örnek 8 & 92 & 90 & 50 & 80 & 12 & 10 & -30 & $-465,517$ & 2,775 & 12,500 & 0,500 & 0,977820349 & 1,110 & 1,000 & $\mathbf{0 , 2 7 1}$ \\
\hline
\end{tabular}

\section{Kaynakça}

Bai, D. S. ve Choi, S. S. (1997). Process capability indices for skewed populations. MS Thesis, Dept. Industrial Engineering, Advanced Institute of Science and Technology, Taejon, South Korea.

Barnett, N. S. (1996). Process control and product quality: the Cp and Cpk revisited. International Journal of Quality and Reliability Management, 7(5): 34-43.

Boyles, R.A. (1994). Process capability with asymmetric tolerances. Communications in Statistics: Simulation and Computation, 23(3):615-643. 
Castagliola, P. (1996). Evaluation of Non Normal Process Capability Indices using Burr's Distributions. Quality Engineering, 8(4):587-593.

Chan, L. K., Cheng, S. W. ve Spiring, F. A. (1988). A new measure of process capability: Cpm. Journal of Quality Technology, 20(3):162-175

Chang, Y. S., Choi, I. S. ve Bai, D. S. (2002). Process capability indices for skewed populations. Quality and Reliability Engineering International, 18(5):383-393.

Chatterjee, M. ve Chakraborty, A. K. (2017). Unification of some multivariate process capability indices for asymmetric specification region. Statistica Neerlandica, 71(4): 286-306.

Chen, K. S. ve Pearn, W. L. (2001), Capability indices for processes with asymmetric tolerances. Journal of the Chinese Institute of Engineers, 24:559-568.

Chen, K. S. (1998). Incapability index with asymmetric tolerance. Statistica Sinica, 8:253-262.

Chen, K. S., Pearn, W. L. ve Lin, P. C. (1999). A new generalization of the capability index $\mathrm{C}, \mathrm{m}$ for asymmetric tolerances. International Journal of Reliability, Quality and Safety Engineering, 6(4):383-398.

Chen, K. S., Wang, K. J. ve Chang, T. C. (2017). A novel approach to deriving the lower confidence limit of indices $\mathrm{Cpu}, \mathrm{Cpl}$, and $\mathrm{Cpk}$ in assessing process capability. International Journal of Production Research, 55(17): 49634981.

Choobineh, F. ve Branting, D. (1986): A simple approximation for semivariance. European Journal of Operations Research, 27, 364-370.

Clements, J. A. (1989). Process capability calculations for non-normal distributions. Quality Progress, September, 95-100.

Coleman, D. E. (1991). Relationships between loss and capability indices. Applied Math. Comp. Techn., ALCOA Technical Center, PA.

Dianda, D. F., Quaglino, M. B., ve Pagura, J. A. (2015). Performance of multivariate process capability indices under normal and non-normal distributions. Quality and Reliability Engineering International, 32(7): 2345-2366.

Dündar, S. ve Şehirlioğlu, A.K. (2014). Pearson Dağılımlarının Ön Bilgi ile Belirlenmesi. Makine Teknolojileri Elektronik Dergisi, (11) 41-59. 
Elderton, W. P., ve N. L. Johnson. (1969). Systems of Frequency Curves. Cambridge University Press, London.

Franklin, L. A. ve Wasserman, G. S. (1991). Bootstrap lower confidence limits for capability indices. Journal of Quality Technology, 24(4):196-210.

Franklin, L. A. ve Wasserman, G. S. (1992). Bootstrap lower confidence limits estimates for $\mathrm{C}_{\mathrm{jkp}}$ (the new flexible process capability indices), Pakistan Journal of Statistics, 10(1):33-45.

Gensidy, A. (1985). Cp and Cpk. Quality Progress, 18(4):7-8.

Hsu, C. H., Chen, K. S. ve Yang, C. M. (2016). Construction of closed interval for process capability indices $\mathrm{Cpu}, \mathrm{Cpl}$, and Spk based on Boole's inequality and de Morgan's laws. Journal of Statistical Computation and Simulation, 86(18): 3701-3714.

Kahraman, C., Parchami, A., Çevik Onar, S. ve Öztayşi. B. (2017). Process capability analysis using intuitionistic fuzzy sets. Journal of Intelligent \& Fuzzy Systems, 32: 1659-1671.

Kane, V. E. (1986). Process capability indices. Journal of Quality Technology, 18(1):41-52.

Kashif, M., Aslam, M., Al-Marshadi, A. H. ve Jun, C. H. (2016). Capability indices for non-normal distribution using Gini's mean difference as measure of variability. IEEE Access, 4: 7322-7330.

Kotz, S. ve Johnson, N. L. (2002). Process capability indices - a review, 19922000. Journal of Quality Technology, 34(1):2-53.

Kotz, S. ve Lovelace C. R. (1998). Process Capability Indices in Theory and Practice, Arnold, London, U.K.

Kotz, S. ve Johnson N.L. (1993). Process Capability Indices. London: Chapman\&Hall, s.53.

Maravelakis, P. E. (2016). Process capability indices for data following the poisson or binomial distribution. Quality Technology \& Quantitative Management, 13(2): 197-206.

Mondal, S. C. (2015). Process capability-a surrogate measure of process robustness: a case study. International Journal of Quality \& Reliability Management, 33(1): 90-106. 
Pan, J. N., Li, C. I. ve Shih, W. C. (2016). New multivariate process capability indices for measuring the performance of multivariate processes subject to non-normal distributions. International Journal of Quality \& Reliability Management, 33(1): 42-61.

Parchami, A., Sadeghpour-Gildeh, B., Nourbakhsh, M. ve Mashinchi, M. (2014). A new generation of process capability indices based on fuzzy measurements. Journal of Applied Statistics, 41(5): 1122-1136.

Pearn, W. L., Kotz, S. ve Johnson, N. L. (1992). Distributional and inferential properties of process capability indices. Journal of Quality Technology, 24(4): 216-231.

Pearn, W. L., Lin, P. C. ve Chen, K. S. (2001). Estimating process capability index for asymmetric tolerances: distributional properties, Metrika, 54:261 -279 .

Piña-Monarrez, M. R., Ortiz-Yañez, J. F. ve Rodríguez-Borbón, M. I. (2015). Non-normal capability indices for the weibull and lognormal distributions. Quality and Reliability Engineering International, 32(4): 1321-1329.

Polansky, A. M. (1998). A smooth nonparametric approach to process capability. Quality and Reliability Engineering International, 14:43-48.

Porter, L. J. ve Oakland, J. S. (1991). Process capability indices - an overview of theory and practice. Quality and Reliability Engineering International, $7: 437-448$.

Rezaye Abbasi Charkhi, M., Aminnayeri, M. ve Amiri, A. (2016). Process capability indices for logistic regression profile. Quality and Reliability Engineering International, 32(5): 1655-1661.

Rodriguer, R. N. (1992). Recent developments in process capability analysis. Journal of Quality Technology, 24:176-187.

Seifi, S. ve Nezhad, M. S. F. (2017). Variable sampling plan for resubmitted lots based on process capability index and Bayesian approach. The International Journal of Advanced Manufacturing Technology, 88: 2547-2555.

Senvar, Ö. ve Kahraman, C. (2014). Type-2 fuzzy process capability indices for non-normal processes. Journal of Intelligent \& Fuzzy Systems, 27(2): 769781.

Senvar, Ö. ve Kahraman, C. (2014a). Fuzzy process capability indices using Clements' method for non-normal processes. Journal of Multiple-Valued Logic Soft Computing, 22(1): 95-121. 
Shore, H. (1998). A new approach to analyzing non-normal quality data with application to process capability analysis. International Journal of Production Research, 36(7):1917-1933.

Somerville, S. E. ve Montgomery, D. C. (1996). Process capability indices and non-normal distributions. Quality Engineering, 9(2):305-316.

Sullivan, L.P. (1984). Reducing Variability: A New Approach to Quality. Quality Progress, 17(7):15-21.

Tang, L. C, Than, S. E. ve Ang, B. W. (1997). A graphical approach to obtaining confidence limits of Cpk. Quality and Reliability Engineering International, 13:337- 346 .

Vannman, K. (1997). A general class of capability indices in the case of asymmetric tolences. Communication in Statistics: Theory and Methods, 26(8):2049-2072.

Wu, H-H., Swain, J. J., Farrington, P.A. ve Messimer, S. L. (1999). A weighted variance capability index for general non-normal processes. Quality and Reliability Engineering International, 15, 397- 402.

Yang, J., Tingting, G., Yuan, C. ve Min, X. (2014). Process capability indices based on the highest density interval. Quality and Reliability Engineering International, 31(8): 1327-1335. 


\title{
A Research on Capability Analysis Methods Used in Cases of Non- Normality Distributed Process Data
}

\author{
Extended Abstract
}

\section{Introduction}

Process capability indices are indicators that outline the ability of production processes to meet the specification limits (tolerances) of products produced in these processes. In the first studies for statistical measurement of process capability, some assumptions must first be proved. These assumptions are that the process is under control (stability), that the product outputs are of approximately normal distribution, and that the tolerances are symmetric around a target value. In the 1990's, process capability index development was commenced in cases where process characteristics are not normal. These studies can be summarized as applying transformation techniques to normalize data, developing process capability indices for known specific distributions (Burr Distribution, Log-normal Distribution, Weibull Distribution etc.), applying robust techniques, and introducing new indices for asymmetric distributions. In each of these studies, however, tolerance limits were considered symmetrically. However, in recent years a number of approaches have been proposed for process ability indices that can be used for processes with asymmetric distribution and symmetric tolerance. One of these suggestions is the use of data transformation techniques such as the Box-Cox transformation, Johnson transformation, and Quantile transformation. A second method is to work with an experimental distribution, or a known distribution with three to four parameters, instead of an unknown distribution. A third method is to rearrange the standard definitions of process ability indices to increase robustness. A fourth method is the use of experimental arguments to develop new indices. Recent studies have focused on Bayesian approaches, fuzzy systems, application examples for different process distributions, and multivariate process capability indices in the calculation of process capability indices.

The aim of this study is to provide an index that has asymmetric tolerance of quality characteristic and can also be used in cases where the distribution of process data is not normal.

\section{Method}

In the study, we utilized the Pearson family of distributions to find out what asymmetric distribution should be desired to be produced by the manufacturing process and to determine how close the data produced by the manufacturing process actually came to this desired distribution. The index proposed in the study to measure the ability of processes that have asymmetric tolerance and show asymmetric or symmetric distribution is as follows:

$$
C_{p a c}=\min \left\{\left[\frac{U S L-m}{U-m}\right]\left[1-\frac{|m-T|}{U S L-L S L}\right]\left[1-\frac{\left|\mu_{3}-m_{3}\right|}{(U S L-L S L)^{3}}\right]\left[\frac{B_{2}}{\beta_{2}}\right] ;\left[\frac{m-L S L}{m-L}\right]\left[1-\frac{|m-T|}{U S L-L S L}\right]\left[1-\frac{\left|\mu_{3}-m_{3}\right|}{(U S L-L S L)^{3}}\right]\left[\frac{B_{2}}{\beta_{2}}\right]\right\}
$$

Here the process ability index value was attempted to be obtained by using the $m$ (mode of process distribution), T (target value of quality characteristic), USL (upper specification limit of quality characteristic $\left(r_{1}\right)$ ), LSL (lower specification limit of quality characteristic $\left(r_{2}\right)$ ), $\mathrm{U}$ (upper limit value of process distribution. If the distribution is limited from the right side $r_{1}$, if unlimited from the right side $X_{0,99865}$ ), L (Lower limit value of the process distribution. If the distribution is 
limited from the left side $r_{2}$, if unlimited from the left side $\left.\mathrm{X}_{0,00135}\right), \mu_{3}$ (Skewness value of the base distribution), $m_{3}$ (Skewness value of the process distribution), $\beta_{2}$ (Kurtosis value of the base distribution) and $B_{2}$ (Kurtosis value of the process distribution).

A procedure is also presented to users for $C_{p a c}$ recommended index. Accordingly, the parameters of Pearson Type I distribution $\left(\mathrm{b}_{0}, \mathrm{~b}_{1}, \mathrm{~b}_{2}\right)$, which are the base distribution, along with USL, LSL, $\mathrm{T}$ and $\mu$ values determined for the quality characteristics of the product are obtained first. If the $\mu$ value is unknown, an appropriate average value is taken according to the condition $\mathrm{T}>\mu>(\mathrm{LSL}+\mathrm{USL}) / 2$ for left-skewed cases, and according to $\mathrm{T}<\mu<(\mathrm{LSL}+\mathrm{USL}) / 2$ for right-skewed cases. With these parameters, the first four moments of the base distribution and the value $\beta_{2}$ are calculated. Then, with the sample data taken from the production process, the upper limit value, lower limit value and mode value of the process distribution are determined. Then, the first four moments of the base distribution and the value $\mathrm{B}_{2}$ are calculated. Finally, the values are substituted in the $C_{p a c}$ index and a comparison is made between the process distribution and the base distribution with the related components.

\section{Findings and Results}

In this part of the study, right-skewed situations that may occur in production processes are examined with examples based on base distribution. The effects of changes in the boundaries of the process distributions, mod values, skewness and kurtosis values on the index are discussed in detail. First, a base distribution with mean $\mu=80$, where USL $=100, \mathrm{~T}=75, \mathrm{LSL}=70$ and $\mathrm{T}<\mu<\mathrm{ASL}+\mathrm{LSL} / 2$ is projected. The assumed base distribution is a right-skewed distribution with asymmetric tolerance and asymmetric distribution.In addition, the parameters predicted for different situations and the index values obtained accordingly were obtained. As the lower and upper values of the process distribution approach the specification values, the value obtained from the proposed index increases and thus it is possible to say that the capability of the process has improved. Similarly, the mode of the process distribution being close to the target value of the base distribution, increases the index value. Since the change in skew value causes a decrease in the index value, the process is seen as a component to reduce the capability index value. Therefore, an increase in the skewness value is never desirable. Finally, it was determined that the process capability index value also increased as the value of kurtosis increased.

\section{Conclusion}

The purpose of this study is to propose a new index, which has not been studied so far in literature, that can be used to measure the capability of processes with asymmetric tolerance and asymmetric distribution. It is possible to comment on the ability of the process by comparing the proposed index $C_{p a c}$ with the process distribution and the base distribution obtained from the tolerance limits of the characteristic. The value of the index is obtained by taking into account the distance of the distribution from the target value, the variation in the values of kurtosis and skewness, and the proximity to the lower and upper specification limits.

When the distance between the upper specification limit of the base distribution and the target value is proportional to the distance between the upper limit and mode of the process distribution, the process capability index value will increase as the ratio grows. In other words, process distribution data will contribute positively to the index as it approaches the target value. It is also concluded that the mode of process distribution, close to the target value of the base distribution, increases the index value. The process is a component intended to decrease the capability index 
value, as the change in skewness value will result in a decrease in the index value. Since the growth of the skew value will never be desired, the resulting difference in the skew value must be examined by the absolute value. The kurtosis value of the process distribution is proportional to the kurtosis value of the base distribution. Increasing the kurtosis value will also increase the process capability index value. 